\title{
Using Indirect Turbulence Measurements for Real-Time Parameter Estimation in Turbulent Air
}

\author{
Borja Martos ${ }^{1}$ \\ University of Tennessee Space Institute, Tullahoma, Tennessee, 37388, USA \\ Eugene A. Morelli ${ }^{2}$ \\ NASA Langley Research Center, Hampton, Virginia, 23681-2199, USA
}

\begin{abstract}
The use of indirect turbulence measurements for real-time estimation of parameters in a linear longitudinal dynamics model in atmospheric turbulence was studied. It is shown that measuring the atmospheric turbulence makes it possible to treat the turbulence as a measured explanatory variable in the parameter estimation problem. Commercial off-theshelf sensors were researched and evaluated, then compared to air data booms. Sources of colored noise in the explanatory variables resulting from typical turbulence measurement techniques were identified and studied. A major source of colored noise in the explanatory variables was identified as frequency dependent upwash and time delay. The resulting upwash and time delay corrections were analyzed and compared to previous time shift dynamic modeling research. Simulation data as well as flight test data in atmospheric turbulence were used to verify the time delay behavior. Recommendations are given for follow on flight research and instrumentation.
\end{abstract}

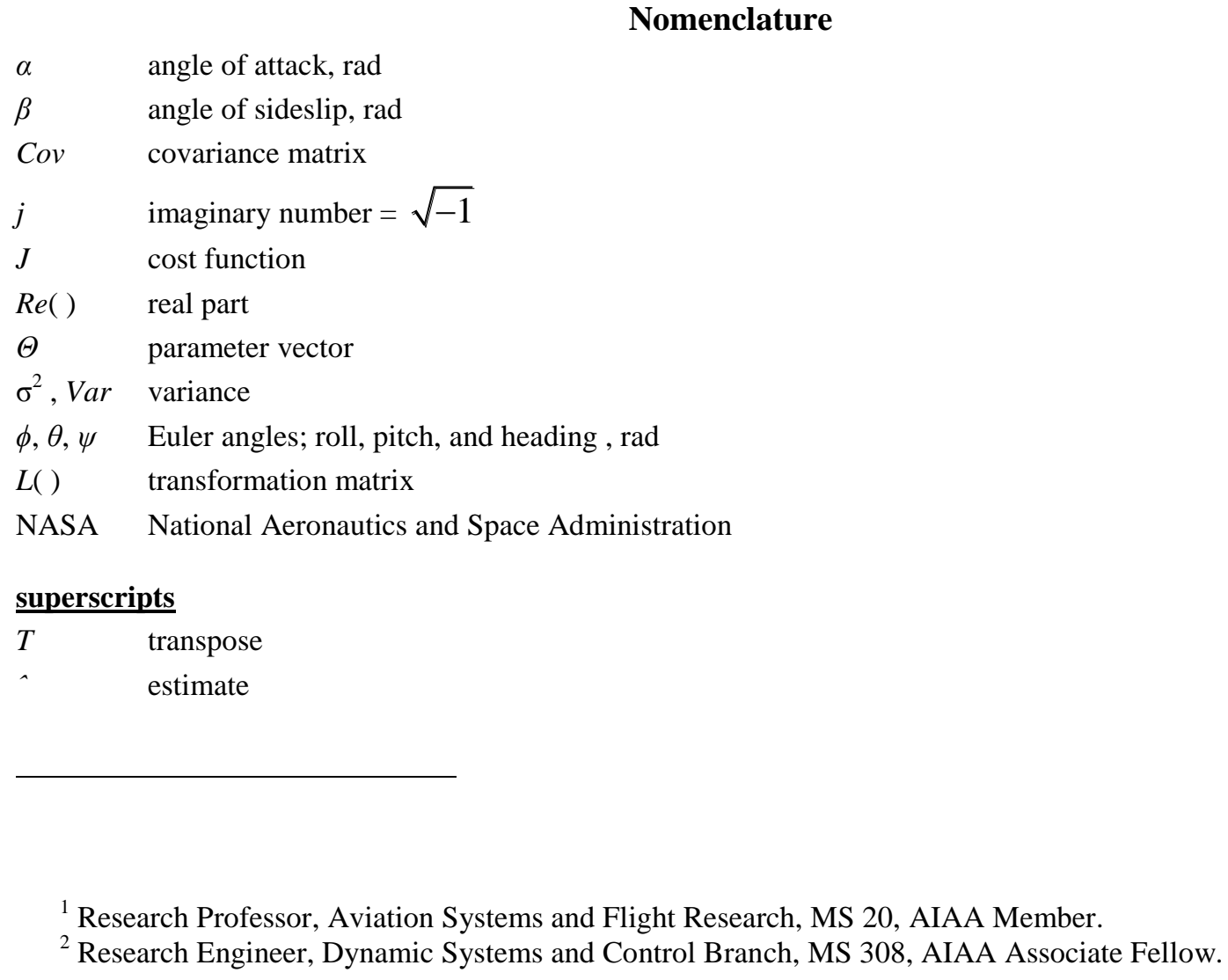




$\begin{array}{ll}\sim & \text { Fourier transform } \\ \cdot & \text { time derivative } \\ -1 & \text { matrix inverse } \\ + & \text { complex conjugate transpose }\end{array}$

\section{Introduction}

In operational flight conditions, an aircraft can encounter atmospheric turbulence and wind shears of varying magnitudes at any time, and many of these atmospheric turbulence encounters can occur in icing clouds. Real-time identification of dynamic models in atmospheric turbulence is a requirement for the Icing Contamination Envelope Protection ICEPro ${ }^{1}$ system. ICEPro performs its function by making real time estimates of the stability and control characteristics of an ice contaminated aircraft in order to provide envelope protection control cues and messages to flight deck displays. By effective use of the cueing on these displays, a pilot is able to mitigate a potentially hazardous icing encounter by avoiding flight conditions and configurations that can result in an upset condition.

The three most prevalent methods for identifying dynamic models from flight data are output error, equation error, and filter error. It has been shown that output error and equation error methods yield biased estimates of dynamic model parameters in the presence of atmospheric turbulence ${ }^{2-3}$. The output error method assumes measurement noise exists but not state noise, whereas equation error assumes that state noise exists but not measurement noise. Filter error methods represent the most general approach, where the dynamic system model has both state and measurement noise ${ }^{4}$. If filter error methods are used ${ }^{5-9}$, discriminating signal from noise is implemented through weighting matrices that represent assumed measurement and process noise covariances. In this case, adjustment of one or more tuning parameters must be done in simulation. For real-time applications, the required tuning and computational expense of filter error methods makes them difficult to apply in practice.

Simulation studies accomplished for this work showed that if the atmospheric turbulence could be measured accurately, then real-time parameter estimation developed in previous work ${ }^{10,11}$ could be applied directly to obtain accurate real-time parameter estimates in atmospheric turbulence, by treating the turbulence as a measured input in the aircraft dynamic model. This motivated a search for flight hardware that could accurately measure the turbulence.

To explore the feasibility of the successful atmospheric turbulence simulation findings, commercial of the shelf (COTS) atmospheric turbulence sensors were investigated and compared against airdata booms. This approach makes it possible to treat the turbulence as a measured explanatory variable in the parameter estimation problem, and enables the use of equation error in the frequency domain, which does not involve tuning parameters, has very low computational requirements, and can be done in real time.

Following the investigation on COTS atmospheric turbulence sensors, several potential sources of colored noise in the explanatory variables are investigated. These include: frequency response of airflow angle vanes, wing aerodynamic response in atmospheric turbulence, and the structural response of the air data boom. Numerical experiments using simulated and flight test data are included to support the investigation of each colored noise source. The simulated data come mainly from a linear DHC-6 Twin Otter simulation. Noise sequences similar to those observed in real flight data analysis and modeling were added to simulated aircraft responses. This approach makes it possible to identify practical problems and solutions regarding the parameter estimation, because the true parameter values are known from the simulation. Flight test results from DHC-6 Twin Otter aircraft are then compared and contrasted to numerical experiments for each of the identified error sources. Following this analysis, conclusions are made and recommendations are given for follow-on flight research and instrumentation. In general, all of the tools used to generate the results shown in the paper are available in a MATLAB ${ }^{\circledR}$ software package called

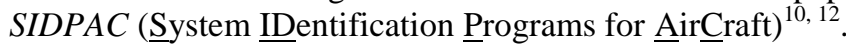




\section{Atmospheric Turbulence Sensors}

\section{A. Background}

In general, atmospheric turbulence is measured indirectly, because atmospheric turbulence is imbedded in the true airspeed measurement. The wind velocity vector $\vec{V}_{w}$ relative to the surface of the Earth is found from the vector subtraction:

$$
\vec{V}_{w}=\vec{V}_{t}-\vec{V}_{e}
$$

where $\vec{V}_{t}$ is the true airspeed and $\vec{V}_{e}$ is the velocity of the aircraft with respect to the Earth, where the Earth is assumed to be an inertial reference. Because $\vec{V}_{w}$ is computed as the difference between two large quantities, it is essential that $\vec{V}_{t}$ and $\vec{V}_{e}$ be measured as accurately as possible in order minimize errors in the computed $\vec{V}_{w}$. The most obvious difficulty in measuring atmospheric turbulence using a sensor mounted on the aircraft is removing the aircraft velocity with respect to the Earth. Additional difficulties arise because the aircraft distorts the airflow around itself. Once the wind velocity vector is calculated it can be treated as an explanatory variable in the parameter estimation problem. Any inaccuracies in the measurements or calibrations will affect the calculated wind velocity vector and in turn the parameter estimates.

A number of atmospheric turbulence sensors have been developed over the years. Although successful measurements are possible using a simple 3-axis accelerometer system to determine the response of the aircraft to gusts of wind ${ }^{13}$, this can be subject to large errors due to the mass of the aircraft damping the response to atmospheric turbulence. Notess ${ }^{14}$ coupled accelerometers with fixed wind vanes and a pitot-static aircraft true air speed (TAS) sensor, whereas Telford and Warner ${ }^{15}$ improved on this system with the introduction of the gyrostabilized platform. Although fixed and rotating vanes ${ }^{16,17}$ have been used to measure airflow relative to the aircraft; it is now more common to use a differential pressure method ${ }^{18-20}$ to avoid the vibration and frequency response problems of long airdata booms. Further refinement of the hemispherical pressure sensing head used to sense flow angles is described by Wyngaard ${ }^{21}$ and Wood $^{22}$. A more advanced instrument is the BAT Probe ${ }^{23-25}$ which uses a nine hole pressure port formation in conjunction with differential GPS and fast-response accelerometers to give wind vector measurements at up to $50 \mathrm{~Hz}$.

\section{B. Theory}

The wind velocity vector is found from the vector subtraction in Eq. (1). The following matrices are used to transform the true airspeed from the flight path axis $\vec{V}_{t}$ to the earth axis $\left(V_{t N}, V_{t E}, V_{t D}\right)^{26-28}$. The multiplication must be performed in the exact order $\beta, \alpha, \phi, \theta, \psi$.

$$
\begin{gathered}
L(\beta)=\left[\begin{array}{ccc}
\cos \beta & -\sin \beta & 0 \\
\sin \beta & \cos \beta & 0 \\
0 & 0 & 1
\end{array}\right] \quad L(\alpha)=\left[\begin{array}{ccc}
\cos \alpha & 0 & -\sin \alpha \\
0 & 1 & 0 \\
\sin \alpha & 0 & \cos \alpha
\end{array}\right] \\
L(\phi)=\left[\begin{array}{ccc}
1 & 0 & 0 \\
0 & \cos \varphi & -\sin \varphi \\
0 & \sin \varphi & \cos \varphi
\end{array}\right] \quad L(\theta)=\left[\begin{array}{ccc}
\cos \theta & 0 & \sin \theta \\
0 & 1 & 0 \\
-\sin \theta & 0 & \cos \theta
\end{array}\right] \quad L(\psi)=\left[\begin{array}{ccc}
\cos \psi & -\sin \psi & 0 \\
\sin \psi & \cos \psi & 0 \\
0 & 0 & 1
\end{array}\right]
\end{gathered}
$$

The matrix transformation from the flight path axis true airspeed to the earth axis (№rth, East, and Down) true airspeed is: 


$$
\left\{\begin{array}{l}
\left(V_{e N}+V_{w N}\right) \\
\left(V_{e E}+V_{w E}\right) \\
\left(V_{e D}+V_{w D}\right)
\end{array}\right\}=L(\psi) L(\theta) L(\phi) L(\alpha) L(\beta)\left\{\begin{array}{c}
V_{t} \\
0 \\
0
\end{array}\right\}
$$

where

$$
\begin{gathered}
V_{w N}=\text { wind speed north } \\
V_{w E}=\text { wind speed east } \\
V_{w D}=\text { wind speed down }
\end{gathered}
$$

From Eq. (4), the wind velocity components are calculated:

$$
\left\{\begin{array}{l}
V_{w N} \\
V_{w E} \\
V_{w D}
\end{array}\right\}=L(\psi) L(\theta) L(\phi) L(\alpha) L(\beta)\left\{\begin{array}{c}
V_{t} \\
0 \\
0
\end{array}\right\}-\left\{\begin{array}{l}
V_{e N} \\
V_{e E} \\
V_{e D}
\end{array}\right\}
$$

Embedded in the wind velocity vector is the atmospheric turbulent air velocity. The effect of atmospheric turbulence at a steady flight condition can be visualized by plotting a time history of the wind vector components and noting the variation in each component.

This theoretical development assumes that the requisite variables are measured without error. Practical implementation of this theory necessitates ground and inflight calibrations to account for boom misalignment, upwash, sidewash, angular rate error, boom bending, and response lag, among others. In typical flight test applications, the Euler attitude angles $\phi, \theta, \psi$ are measured using an inertial navigation system, while the airflow angles are measured using an airdata boom. Any inaccuracies in either measurement system will directly affect the computed wind velocity components. Special emphasis is placed on the word "computed" because the wind velocity components are not directly measured but computed using the vector subtraction in Eq. (5).

\section{COTS sensors}

A search was conducted to identify candidate COTS atmospheric turbulence sensors. Several sensors were identified using state of the art $\operatorname{LIDAR}^{29}$ technology with an airflow angle accuracy of 1.0 degrees. In comparison, flight test air data booms with traditional air data technology are calibrated to an accuracy of 0.1 degrees. The cutoff accuracy for this work was set at 0.1 degrees. Unfortunately, the accuracy of LIDAR based sensors requires an order of magnitude improvement to be useful for the present work. Several additional sensors were identified using traditional air data technology ${ }^{30,31}$. The AIMMS-20 probe by Avantech Research ${ }^{31}$ was chosen for further investigation because it provides the most accurate wind determination of all the candidate sensors. The AIMMS-20 probe incorporates state-of-the-art technology including differential GPS and miniaturized components, and makes use of Kalman Filter signal processing algorithms. Table 1 summarizes the AIMMS-20 performance.

A quantitative comparison between the AIMMS-20 probe and typical flight test air data and inertial instrumentation will yield similar performance specifications for the measurements they have in common. The advantage of the AIMMS-20 probe is that it is packaged as a COTS system. The disadvantage of the AIMMS-20 probe and all of the other COTS products identified is that atmospheric turbulence is not measured directly but computed. Hence, the COTS solutions are no different than applying the theory to flight test hardware, such as an air data boom and an inertial navigation system with differential GPS. Furthermore, any errors that affect an air data boom and an inertial navigation system will also affect the COTS atmospheric turbulence sensors. Therefore, it was found that current COTS atmospheric turbulence sensors do not offer an advantage over modern flight test hardware. 
Table 1 AIMMS-20 probe performance

\begin{tabular}{|l|c|}
\hline \multicolumn{1}{|c|}{ Parameter } & 1 Sigma Error \\
\hline Longitudinal acceleration, $\mathrm{A}_{\mathrm{X}},(\mathrm{g})$ & 0.003 \\
\hline Lateral acceleration, $\mathrm{A}_{\mathrm{Y}},(\mathrm{g})$ & 0.003 \\
\hline Normal acceleration, $\mathrm{A}_{\mathrm{Z}},(\mathrm{g})$ & 0.05 \\
\hline Angle of Attack, $\alpha,(\mathrm{deg})$ & 0.10 \\
\hline Angle of Sideslip, $\beta,(\mathrm{deg})$ & 0.10 \\
\hline Pitch rate, $\mathrm{q},(\mathrm{dps})$ & 0.01 \\
\hline Roll rate, $\mathrm{p},(\mathrm{dps})$ & 0.07 \\
\hline Yaw rate, $\mathrm{r},(\mathrm{dps})$ & 0.01 \\
\hline Pitch attitude, $\theta,(\mathrm{deg})$ & 0.20 \\
\hline Roll attitude, $\phi,(\mathrm{deg})$ & 0.20 \\
\hline Yaw attitude, $\psi,(\mathrm{deg})$ & 0.20 \\
\hline GPS velocity down, $\mathrm{V}_{\mathrm{D}},(\mathrm{mps})$ & 0.10 \\
\hline GPS velocity north, $\mathrm{V}_{\mathrm{N}},(\mathrm{mps})$ & 0.10 \\
\hline GPS velocity east, $\mathrm{V}_{\mathrm{E}},(\mathrm{mps})$ & 0.10 \\
\hline True airspeed, $\mathrm{V}_{\mathrm{T}},(\mathrm{mps})$ & 0.20 \\
\hline Wind velocity down, $\mathrm{W}_{\mathrm{D}},(\mathrm{mps})$ & 0.30 \\
\hline Wind velocity north, $\mathrm{W}_{\mathrm{N}},(\mathrm{mps})$ & 0.30 \\
\hline Wind velocity east, $\mathrm{W}_{\mathrm{E}},(\mathrm{mps})$ & 0.30 \\
\hline \hline
\end{tabular}

III. Problem Statement

The following results are representative of the effect of atmospheric turbulence on aircraft dynamic model parameter estimates. Data were collected using the NASA Langley AirSTAR T-2 subscale generic transport aircraft during low and high atmospheric turbulence conditions. The T-2 aircraft is a 5.5 percent dynamically-scaled generic twin-engine jet transport aircraft. It is outfitted with flight test instrumentation and air data booms with flow vanes on each wingtip. Figure 1 shows a photograph of the aircraft in flight.

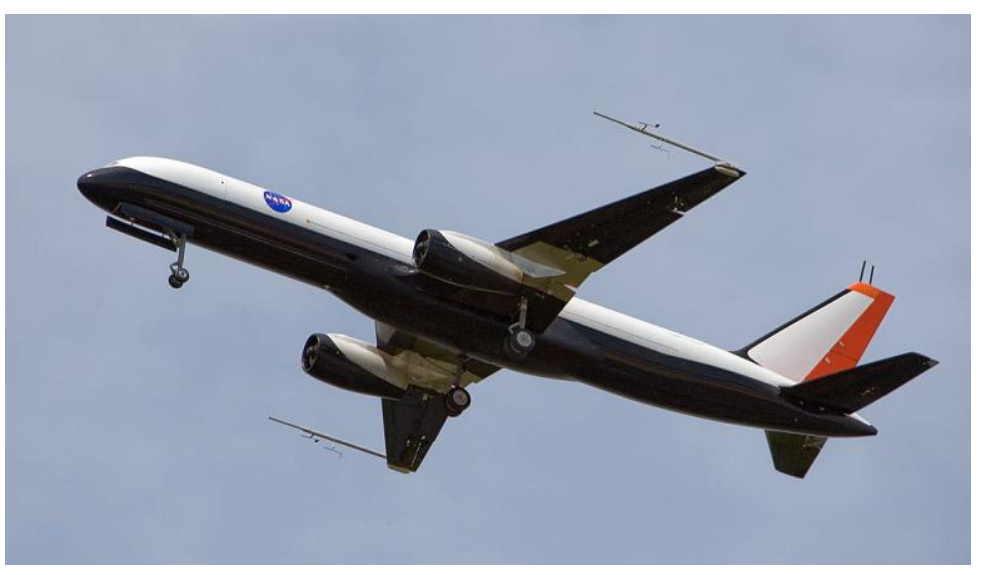

Figure 1. T-2 subscale jet transport aircraft Credit: NASA Langley Research Center 
Figure 2 shows parameter estimation results from T-2 flight test data using equation-error in the frequency domain. Each marker represents a different run, and only the last estimate of each real-time parameter estimation run is shown. A total of nine runs are represented; six in high turbulence and three in low turbulence.
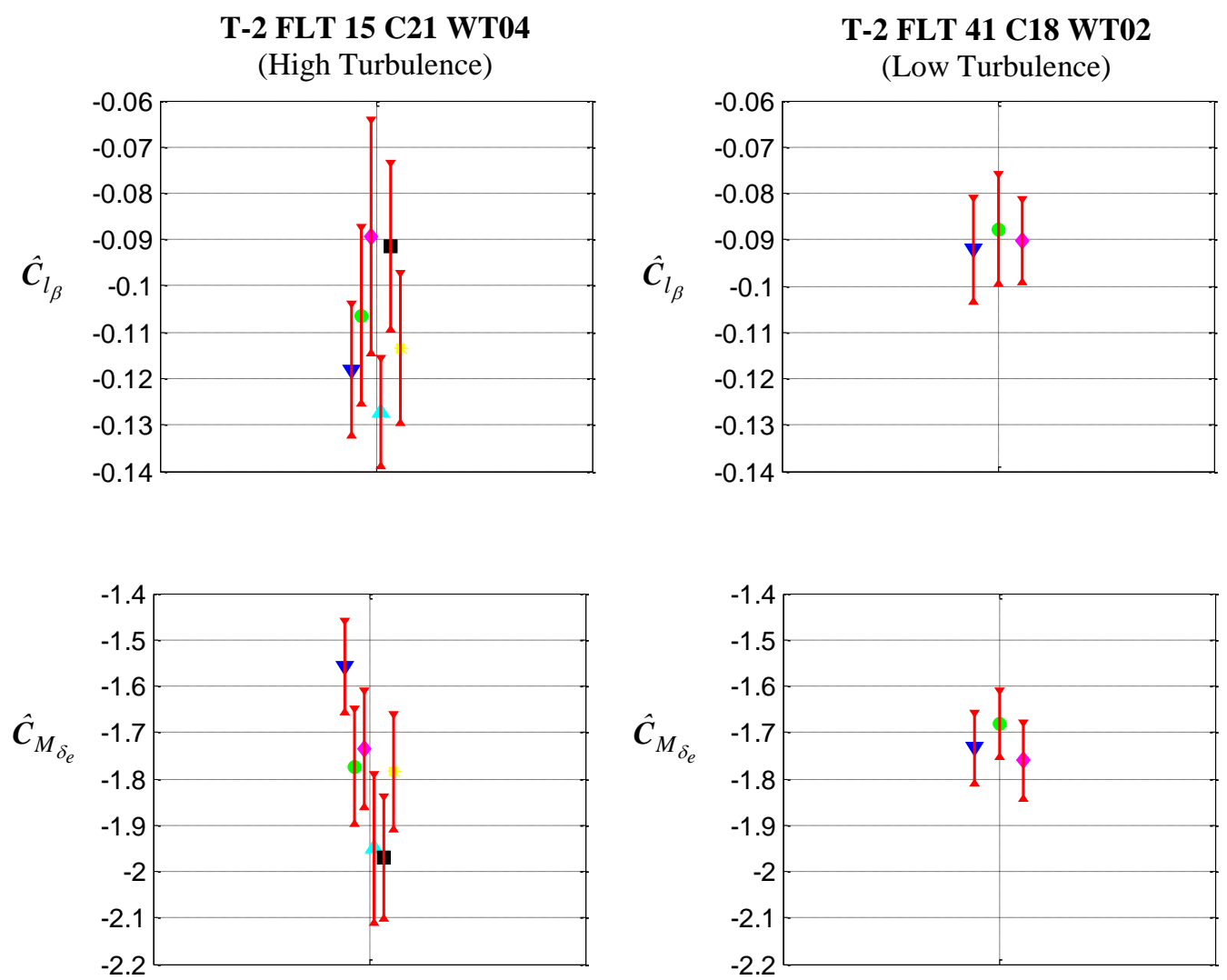

Figure 2. Effect of atmospheric turbulence on T-2 modeling results

Determining exactly what characteristic or effect from atmospheric turbulence causes the bias and scatter in the parameter estimation results is an ongoing research topic. It is known that colored noise in the explanatory variables or model outputs causes increased uncertainty and bias $^{2,3,10}$ in the parameter estimates, similar to what is observed in Figure 2 during repeated flight test maneuvers in high atmospheric turbulence. It is unknown whether the turbulence causes colored noise in the explanatory variables and/or outputs, or if the observed bias and uncertainty in the parameter estimates in turbulence are from some other cause.

\section{A. Hypothesis}

Colored noise in the explanatory variables is the source of bias and increased uncertainty in the parameters estimated in high atmospheric turbulence.

\section{B. Sources of colored noise}

Possible sources of colored noise in the explanatory variables include: frequency response of airflow angle vanes, frequency response of the boom, wing aerodynamic response to atmospheric turbulence, pitot-static frequency response, and airframe structural dynamics, among others. Since the airflow angles $\alpha$ and $\beta$ are the explanatory variables with the largest contribution in the dynamic modeling process, the focus will be on these quantities. The effects of the frequency response of airflow angles vanes, the wing aerodynamic response in atmospheric turbulence, and the structural response of the air data boom will be considered using simulation and flight test data. 


\section{Frequency response of airflow angle vanes}

In order to investigate the frequency response of airflow angle vanes, an airflow vane sensor model was studied. A natural frequency of $\omega_{n}=9 \mathrm{~Hz}$ and a damping ratio $\zeta=0.35$ were chosen as representative values for a dynamic model of the airflow vanes ${ }^{32-34}$. Typical natural frequency and damping ratio values range from $5-20 \mathrm{~Hz}$ and 0.2-0.6 respectively. Eq. (6) represents a second order continous-time transfer function.

$$
G(s)=\frac{\omega_{n}^{2}}{s^{2}+2 \zeta \omega_{n} s+\omega_{n}^{2}}
$$

The transfer function representation does not support non-zero initial conditions; therefore, the vane sensor model was converted to a state space representation which supported a trim $\alpha$ initial condition.

\section{Wing aerodynamic response in atmospheric turbulence}

A DHC-6 Series 300M Twin Otter research aircraft was used to study the aerodynamic effects on atmospheric turbulence measurements ${ }^{35}$. Details of the aircraft and its instrumentation system are found in Ref. [35]. A flush air data system mounted on the nose of the Twin Otter was used as the primary source of airdata measurements. Flush air data systems avoid the vibration and frequency response problems of long booms mounted on the nose of the research aircraft but require extensive calibrations ${ }^{36}$.

It was determined ${ }^{35}$ that a major flow distortion, which seriously affects the vertical wind velocity measurements near the nose of an aircraft, is the frequency dependent upwash and time delay. These are shown to be the result of not taking into account the decrease in upwash correction with eddy frequency caused by the response of the wing vortex system to atmospheric turbulence, and the longitudinal distance between the angle of attack sensor and the leading edge of the wing, respectively.

The unsteady aerodynamic analysis detailed in Ref. [35] with flight data from NASA's DHC-6 Series 100 Twin Otter aircraft was used to calculate the angle of attack upwash and time delay as a function of frequency. The required upwash correction and time delay is summarized in Figure 3 and Figure 4 during flight in light and moderate turbulence. Similar results are found in Ref. [35].

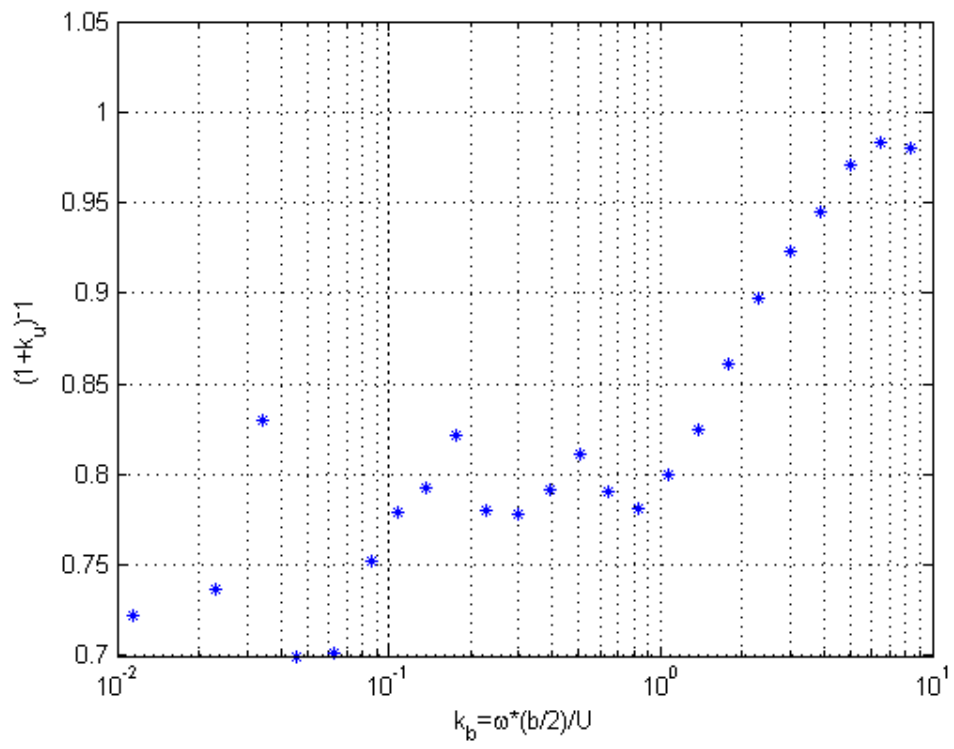

Figure 3. Angle of attack upwash correction versus frequency

Figure 3 represents the estimated angle of attack scale factor correction vs. frequency. The frequency scale is the reduced frequency $\mathrm{k}_{\mathrm{b}}$ based on the half wing span where $\omega$ is the angular frequency, $b$ is the wingspan, and $U$ is the airspeed. The angle of attack upwash correction $\left(1+k_{u}\right)^{-1}$ is explained by examining a sensor model: 


$$
\alpha_{M}=\left(1+k_{u}\right) \alpha_{T}+\alpha_{B}
$$

where

$$
\begin{gathered}
\alpha_{B}=\text { bias angle of attack } \\
\alpha_{M}=\text { measured angle of attack } \\
\alpha_{T}=\text { true angle of attack }
\end{gathered}
$$

In Figure 3, the vertical axis $\left(1+k_{u}\right)^{-1}$ represents the correction required to calculate the true angle of attack from measured data.

$$
\alpha_{T}=\left(1+k_{u}\right)^{-1}\left(\alpha_{M}-\alpha_{B}\right)
$$

At low frequencies (representing flight in a calm atmosphere) the scale factor is approximately 0.75 and increases to 0.90 as $\mathrm{k}_{\mathrm{b}}$ approaches 2.0. A $\mathrm{k}_{\mathrm{b}}$ value of 2.0 (using the DHC-6 Twin Otter wing span and $110 \mathrm{knot}$ cruise airspeed) corresponds to approximately $2.0 \mathrm{~Hz}$. Therefore, over the frequency range of interest for rigid body aircraft dynamics $(0.1$ to $2.0 \mathrm{~Hz})$, the scale factor changes from 0.75 to 0.90 due to atmospheric turbulence.

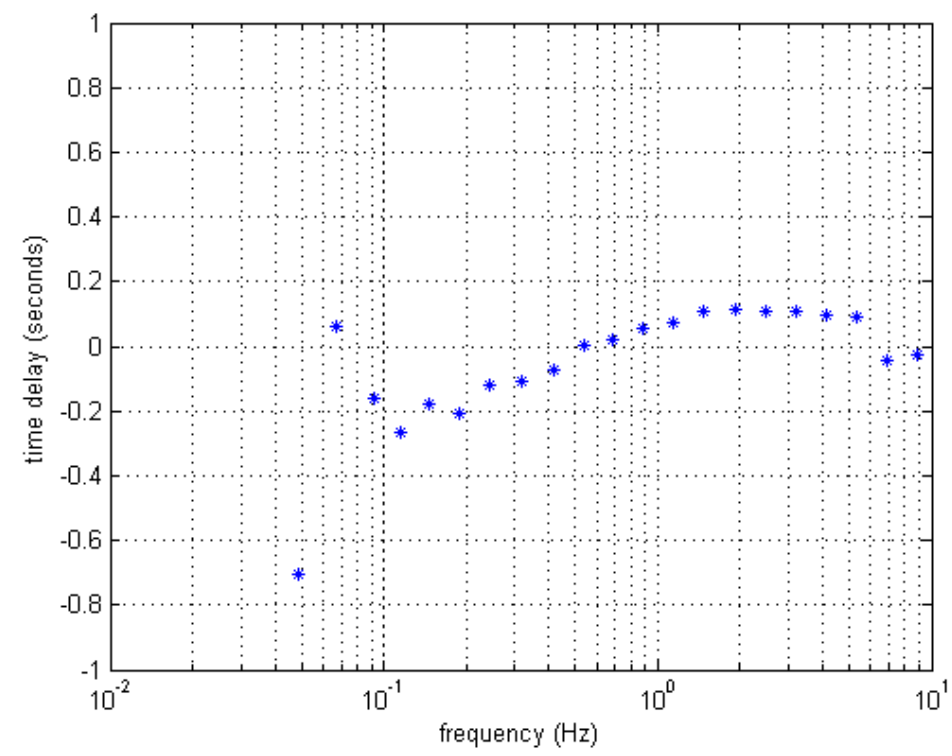

Figure 4. Time delay versus frequency

Figure 4 depicts the time delay as a function of frequency. The time delay is caused by the separation between the nose boom mounted airflow vanes (measurement position) and the wing tip (lift and upwash generation), along which turbulence eddies travel. The magnitidue of the time delay represents the correction required to calculate the true angle of attack from measured data. In the frequency range of interest for rigid body aircraft dynamics (0.1 to $2.0 \mathrm{~Hz}$ ), the time delay is approximately 0.1 seconds. A general description of unsteady aerodynamic theory at the nose of the aircraft and its calculations are found in the seminal paper ${ }^{35}$.

A data compatibility ${ }^{10}$ analysis was used to reconstruct the angle of attack from flight test measurements and compare it to the measured angle of attack. Three runs were evaluated at similar airspeeds (120 knots) and aircraft configurations. The first run represents a calm atmosphere; the next two runs represent atmospheric turbulence. 

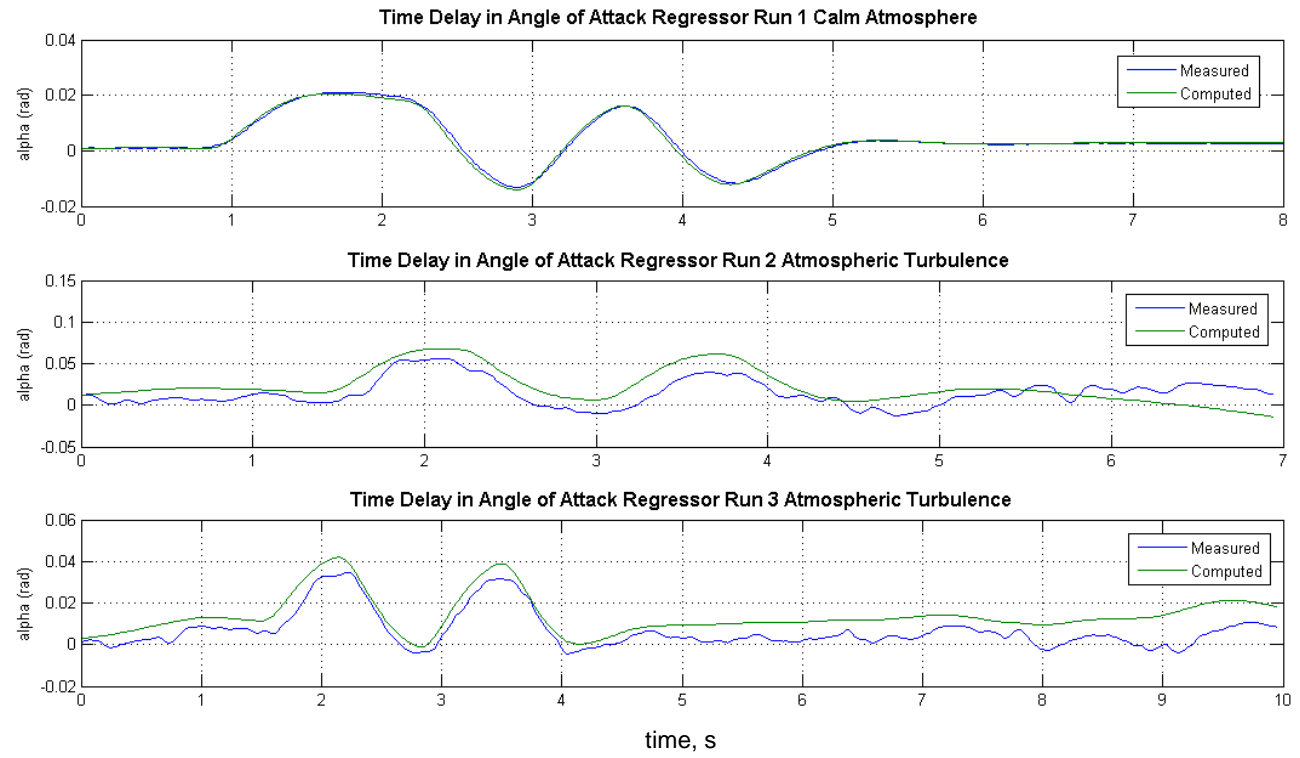

Figure 5. Angle of attack time delay in atmospheric turbulence

In Figure 5, run 1 in calm atmospheric conditions shows a time delay of approximately 0.03 seconds. Runs 2 and 3 in atmospheric turbulence show a time delay of approximately 0.13 seconds. This agrees with the fact that the time it takes to travel 21 feet (longitudinal distance from the airflow angle measurement position to the center of gravity) at 120 knots is approximately 0.1 seconds. The difference is attributed to forced (elevator doublets) oscillations in run 1 and a combination of forced and atmospheric turbulence oscillations in runs 2 and 3 . This increase in time delay in atmospheric turbulence is a source of degradation in the stability and control parameter estimates.

Another problem with using inertial measurements to reconstruct data such as angle of attack is that the reconstruction assumes the atmosphere is fixed relative to the earth axes. When there are gusts or winds, this assumption is not valid, and the reconstructed data have errors. Since the airflow angles are measured at the nose of the aircraft and the inertial measurements are taken at the center of gravity it is expected that the measured angle of attack will lead the reconstructed inertial angle of attack. The reconstructed angle of attack leads the measured angle of attack and is in error in Figure 5. This is attributed to not accounting for gusts and winds in the data compatibility analysis.

\section{Structural response of air data boom}

In order to investigate the inflight structural response of the airdata boom, airflow angle flight data collected in a DHC-6 Twin Otter during multiple parameter etstimation maneuvers was analyzed in the frequecy domain using Fourier sine series coefficients.

Figure 6 shows the frequency response data for the entire frequency range, up to the Nyquist frequency at $25 \mathrm{~Hz}$. The longitudinal and lateral natural frequencies for the dominant structural mode of the air data boom are approximately 8 and $9 \mathrm{~Hz}$. These natural frequencies are associated with the angle of attack and angle of sideslip measurements respectively. In Figure 6, the Fourier coeffcients near 8 and $9 \mathrm{~Hz}$ are at the noise floor. Therefore, the structural response of the nose boom on which the angle of attack sensor is mounted and from fuselage bending is not a source of colored noise in the angle of attack. Similar results were calculated for angle of sideslip but the results are not shown. 


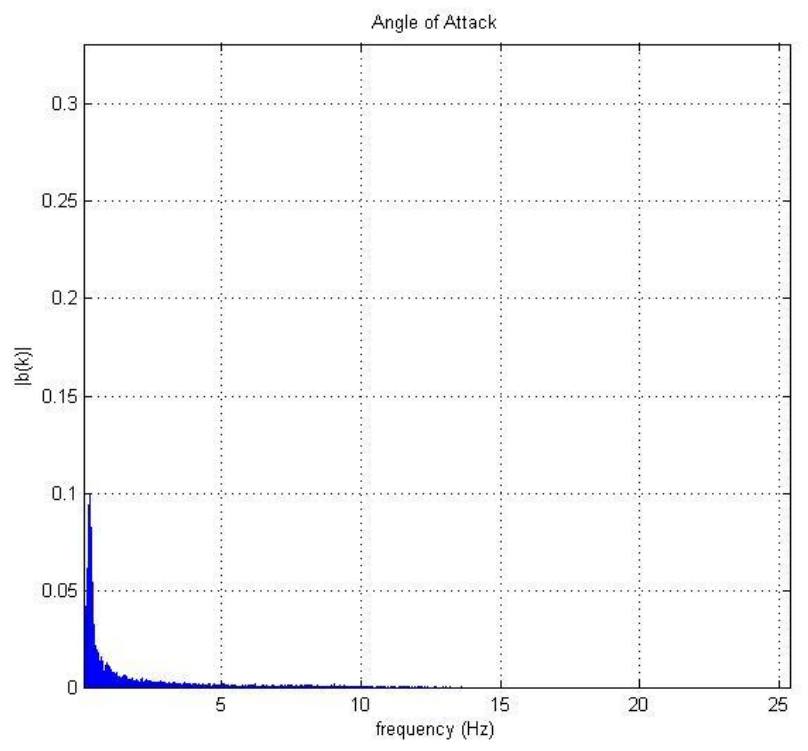

Figure 6. Fourier sine series coefficients for measured angle of attack

\section{Real-Time Parameter Estimation}

Time-domain methods are generally not good for real-time applications due to the iterative nature of the solutions, or trial and error weighting of the formulations, or the fact that estimated parameter error bounds are either inaccurate or require rather involved correction calculations ${ }^{10}$. However, if equation error in the frequency domain is used, the formulation accounts for state noise and is also robust to measurement noise, in addition to providing accurate error bounds without correction calculations. This is due to the automatic filtering inherent in using a limited bandwidth for the recursive Fourier transform ${ }^{11}$ since the rigid-body dynamics of typical piloted aircraft lie in a relatively narrow frequency band of approximately $0.01-2.0 \mathrm{~Hz}$.

The real-time parameter estimation algorithm being employed was developed by Morelli ${ }^{11}$, and is based on a frequency domain approach implemented in version 2.0 of System IDentification Programs for AirCraft (SIDPAC). ${ }^{10,12}$ The approach uses a linearized model of the vehicle dynamics, where $A, B, C$, and $D$ are matrices containing stability and control derivatives.

$$
\begin{aligned}
& \dot{x}(t)=A x(t)+B u(t) \quad x(0)=0 \\
& y(t)=C x(t)+D u(t)
\end{aligned}
$$

In Eqs. (9), the stability and control derivatives to be estimated can be dimensional or non-dimensional ${ }^{10}$. Timevarying estimates of the stability and control derivatives are determined using measured aircraft control surface deflections and measured states from air flow angle data and angular rate data. Outputs are aircraft states and translational accelerations. To determine the model parameter estimates, a cost function is formulated in the frequency domain from the Fourier transform of the model in Eq. (9),

$$
\begin{aligned}
& j \omega \tilde{x}(\omega)=A \tilde{x}(\omega)+B \tilde{u}(\omega) \\
& \tilde{y}(\omega)=C \tilde{x}(\omega)+D \tilde{u}(\omega)
\end{aligned}
$$


The cost function is

$$
J_{k}=\frac{1}{2} \sum_{n=1}^{m}\left|j \omega_{n} \tilde{x}_{k}(n)-a_{k} \tilde{x}(n)-b_{k} \tilde{u}(n)\right|^{2} \text { for } m \text { frequencies }
$$

where $a_{k}$ and $b_{k}$ are the $k$ th row of matrices $A$ and $B$, respectively, and $\tilde{x}_{k}(n) \equiv \tilde{x}_{k}\left(\omega_{n}\right), \tilde{u}_{k}(n) \equiv \tilde{u}_{k}\left(\omega_{n}\right)$. Each line in Eq. (10) can be analyzed separately in this way, which implements an equation-error formulation ${ }^{11}$. The least squares cost function in each case can be formulated as

$$
J=\frac{1}{2}(Y-X \theta)^{\dagger}(Y-X \theta)
$$

where

$$
Y=\left[\begin{array}{c}
j \omega_{1} \tilde{x}_{k}(1) \\
\vdots \\
j \omega_{m} \tilde{x}_{k}(m)
\end{array}\right] \quad X=\left[\begin{array}{cc}
\tilde{x}^{T}(1) & \tilde{u}^{T}(1) \\
\vdots & \vdots \\
\tilde{x}^{T}(m) & \tilde{u}^{T}(m)
\end{array}\right]
$$

and the unknown parameters from $A$ and $B$ are contained in the parameter vector $\theta$. The least squares parameter vector estimate is obtained as the value of $\theta$ that minimizes the cost function in Eq. (12). ${ }^{10}$

$$
\begin{aligned}
& \hat{\theta}=\left[\operatorname{Re}\left(X^{\dagger} X\right)\right]^{-1} \operatorname{Re}\left(X^{\dagger} Y\right) \\
& \operatorname{cov}(\hat{\theta}) \equiv E\left[(\hat{\theta}-\theta)(\hat{\theta}-\theta)^{T}\right]=\hat{\sigma}^{2}\left[\operatorname{Re}\left(X^{\dagger} X\right)\right]^{-1} \\
& \hat{\sigma}^{2}=\frac{1}{m}(Y-X \hat{\theta})^{\dagger}(Y-X \hat{\theta})
\end{aligned}
$$

Performing the identification in the frequency domain is advantageous for this application because of computational efficiency, robustness to noise and data dropouts, and reliable confidence bounds from the covariance matrix. The required Fourier transforms are computed using a recursive formulation, and the calculations in Eq. (14) are done periodically (typically at 1 or $2 \mathrm{~Hz}$ ) to implement real-time parameter estimation, see Refs. [10] and [11] for details.

\section{Aircraft}

The DHC-6 Series 100 Twin Otter is a Canadian 19-passenger Short Takeoff and Landing utility aircraft developed by de Havilland Canada. Figure 7 shows a photograph of the aircraft in flight.

The aircraft has two 550 SHP Pratt and Whitney PT6A-20A turbine engines driving three bladed Hartzell constant speed propellers. The flight controls are mechanically operated through a system of cables and pulleys. Control surfaces consist of elevator, ailerons, rudder, and wing flaps. Table 2 contains mass and geometry properties of the Twin Otter aircraft. 


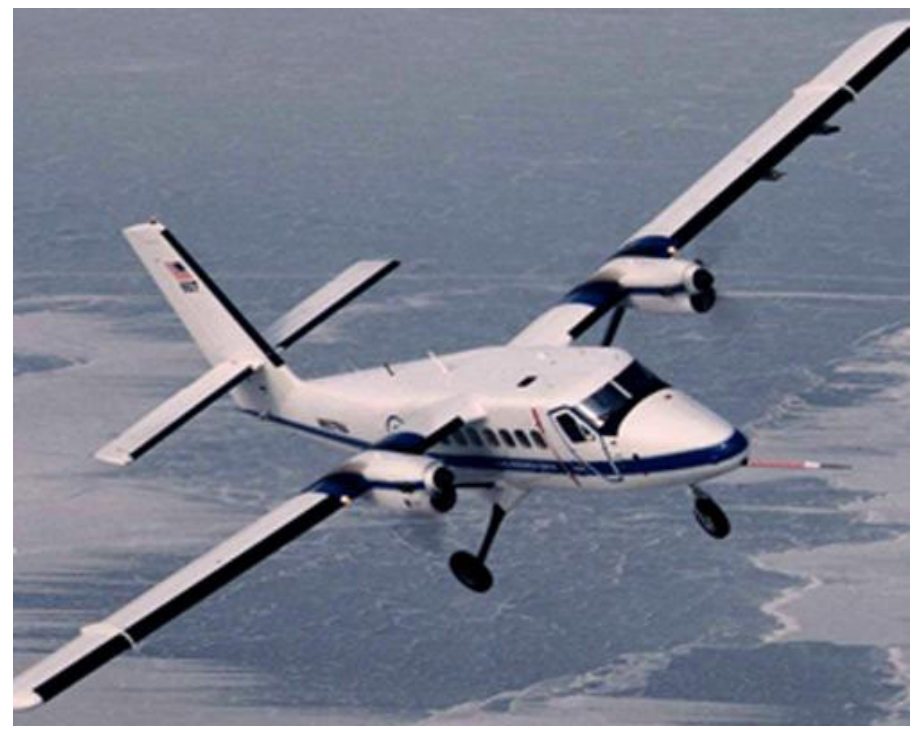

Figure 7. DHC-6 Twin Otter aircraft

Credit: NASA Glenn Research Center

Table 2. Physical properties of the Twin Otter aircraft

\begin{tabular}{|l|c|}
\hline \multicolumn{1}{|c|}{ Property } & Value \\
\hline$m$, slug & 280 \\
\hline Inertia & 16,000 \\
\hline$I_{Y}$, slug-ft ${ }^{2}$ & \\
\hline Wing & 422.5 \\
\hline Area, $\mathrm{ft}^{2}$ & 65 \\
\hline Span, $\mathrm{ft}$ & 6.5 \\
\hline $\begin{array}{l}\text { Mean Aerodynamic Chord, } \\
\mathrm{ft}\end{array}$ & \\
\hline
\end{tabular}

\section{A. Aircraft Simulation}

The flat earth, body axes, longitudinal three degree of freedom model equations can be classified as the force (15), moment (16), kinematic (17), and navigation (18) equations. This formulation was chosen to enable both batch simulations and pilot in the loop simulations with realistic out-the-window visuals. The dynamics were reduced to the three longitudinal degrees of freedom by setting lateral and directional values $v=p=r=\phi=\dot{r}=\dot{p}=0^{10}$ in order to simplify the analysis.

$$
\begin{gathered}
\dot{u}=q w-g \sin \theta+\left(X+T_{X}\right) / m \\
\dot{w}=q u-g \cos \theta+\left(Z+T_{Z}\right) / m \\
I_{Y} \dot{q}=M+M_{T}
\end{gathered}
$$




$$
\begin{gathered}
\dot{\theta}=q \\
\dot{h}=u \sin \theta-w \cos \theta
\end{gathered}
$$

Nondimensional aerodynamic force and moment coefficients for an aircraft can be computed from flight measurements as follows ${ }^{10}$ :

$$
\begin{aligned}
C_{X} & =\left(m a_{X}-T_{X}\right) / \bar{q} S \\
C_{Z} & =\left(m a_{Z}-T_{Z}\right) / \bar{q} S \\
C_{M} & =\left[I_{Y} \dot{q}-M_{T}\right] / \bar{q} S \bar{c}
\end{aligned}
$$

For local modeling over a short time period, the force and moment coefficients computed from Eqs. (19) can be modeled using linear expansions in the aircraft states and controls:

$$
\begin{gathered}
C_{X}=C_{X \alpha} \Delta \alpha+C_{X_{q}} \frac{\Delta q \bar{c}}{2 V}+C_{X \delta e} \Delta \delta e+C_{X_{o}} \\
C_{Z}=C_{Z \alpha} \Delta \alpha+C_{Z_{q}} \frac{\Delta q \bar{c}}{2 V}+C_{Z \delta e} \Delta \delta e+C_{Z_{o}} \\
C_{M}=C_{M \alpha} \Delta \alpha+C_{M_{q}} \frac{\Delta q \bar{c}}{2 V}+C_{M \delta e} \Delta \delta e+C_{M_{o}}
\end{gathered}
$$

The $\Delta$ notation indicates perturbation from a reference condition. In Eq. (20c), $C_{m_{o}}$ represents the nondimensional pitching moment at a reference condition, and similarly for the other expansions. For short periods of time, the stability and control derivatives are considered as constant model parameters to be estimated from flight data.

\section{B. Atmospheric Turbulence model}

Atmospheric turbulence was tested as calm, light, moderate, and severe. Atmospheric turbulence levels and implementation were defined per MIL-F-8785C and were based on the Dryden turbulence spectrum. The atmospheric turbulence velocity components were generated randomly within the guidelines of the Dryden spectrum using individual realizations of random number sequences and added to the aircraft velocity components to generate the total velocity components. This resulted in unique sequences of random numbers for each test. The three velocity components from the atmospheric turbulence calculations were added to their appropriate body frame velocity components $(u, v$, and $w)$ calculated from the aircraft dynamic equations.

$$
\begin{gathered}
u=u_{\text {aerodynamics }}+u_{\text {wind }}+u_{\text {turbulence }} \\
v=v_{\text {aerodynamics }}+v_{\text {wind }}+v_{\text {turbulence }} \\
w=w_{\text {aerodynamics }}+w_{\text {wind }}+w_{\text {turbulence }}
\end{gathered}
$$




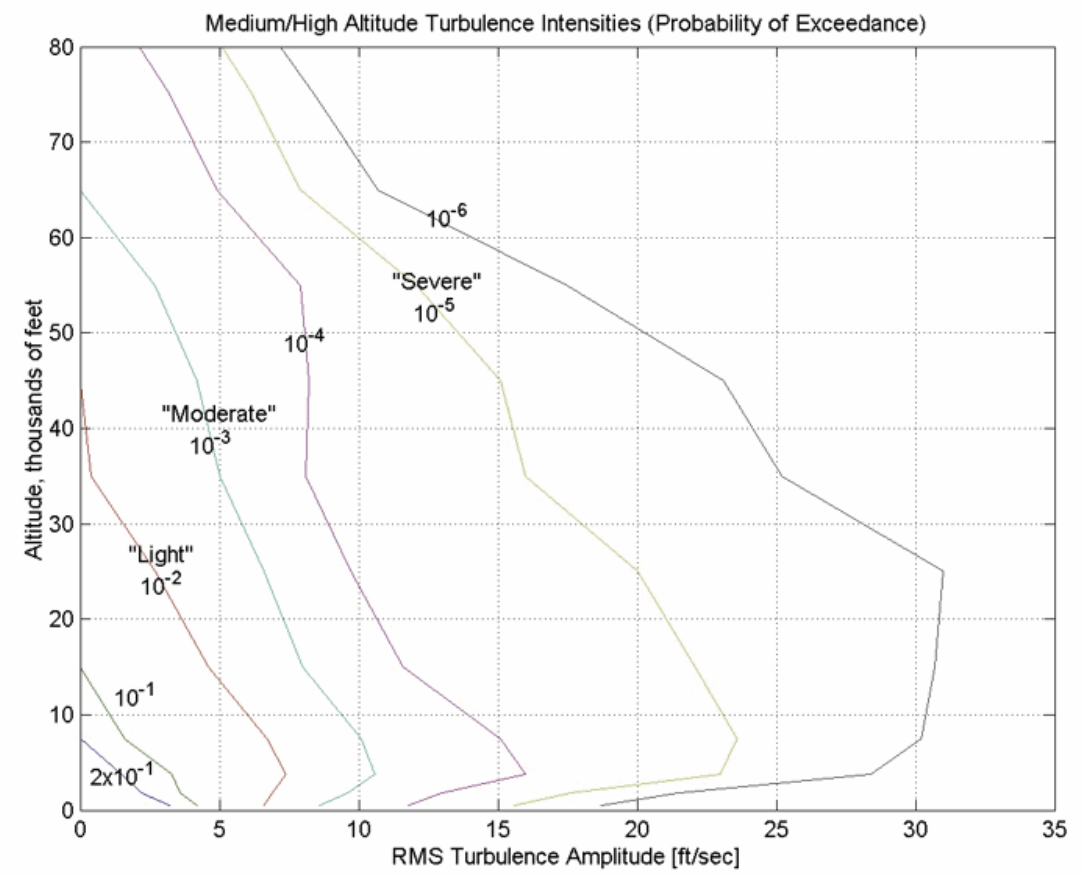

Figure $8 .{ }^{37}$ MIL-F-8785c atmospheric turbulence velocities

The root-mean-square turbulent wind speeds are also shown Figure 8 as a function of altitude. According to MIL-F-8785C, the probability of exceeding light turbulence levels is between $10^{-1}$ and $10^{-2}$, for moderate turbulence, the probability is approximately $10^{-3}$, and for severe turbulence it is approximately $10^{-5}$. Therefore, severe turbulence levels are not likely to be encountered.

\section{Simulation Results}

The hypothesis was tested using a simulation of the DHC-6 Series 100 Twin Otter and the following test conditions:

1) Baseline runs with perfect angle of attack measurements

2) Runs with a representative frequency response model for the airflow angle vanes

3) Repeat test condition 2) with varying angle of attack magnitude and time delay as a function of frequency

The following parameters are common to all three test conditions:

- Aircraft trimmed at 2,500 feet and 110 knots

- 20 second runs

- Real-time parameter estimation method ${ }^{10,11}$, described in Section IV

- Orthogonal multi-sine inputs ${ }^{10}$ invoked from 1 to 11 seconds

- Selected final model parameter estimates from each 20-second run

- 200 runs per atmospheric turbulence intensity (calm, light, moderate, and severe)

- Fourier transform frequency spacing $0.04 \mathrm{~Hz}$

- Fourier transform frequency range $[0.12 .0] \mathrm{Hz}$

- Signal to noise ratio of 50

- $50 \mathrm{~Hz}$ data rate 
The following comments are common to all of the figures associated with test conditions one through three:

- Green line- truth value of the parameter

- Red dashed line - confidence interval using $\pm 10 \%$ of truth value of the parameter

- Red diamond - parameter estimate

- Blue bars - estimated two sigma error bounds

In the dynamic modeling process, no attempt was made at estimating the axial force coefficients, because the aircraft excitations did not appreciably change airspeed, resulting in a low signal-to-noise ratio for the axial force coefficient parameter estimation. In total, six coefficients were estimated, $C_{Z \alpha}, C_{Z q}, C_{Z \delta e}, C_{M \alpha}, C_{M q}$, and $C_{M \delta e}$.

\section{A. Test Condition 1}

As show in Figure 9, the baseline model estimates for $C_{Z \alpha}$ resulted in improved estimates with increasing atmospheric turbulence. This is not representative of actual flight data and is attributed to perfect $\alpha$ measurement given the additional excitation caused by atmospheric turbulence.
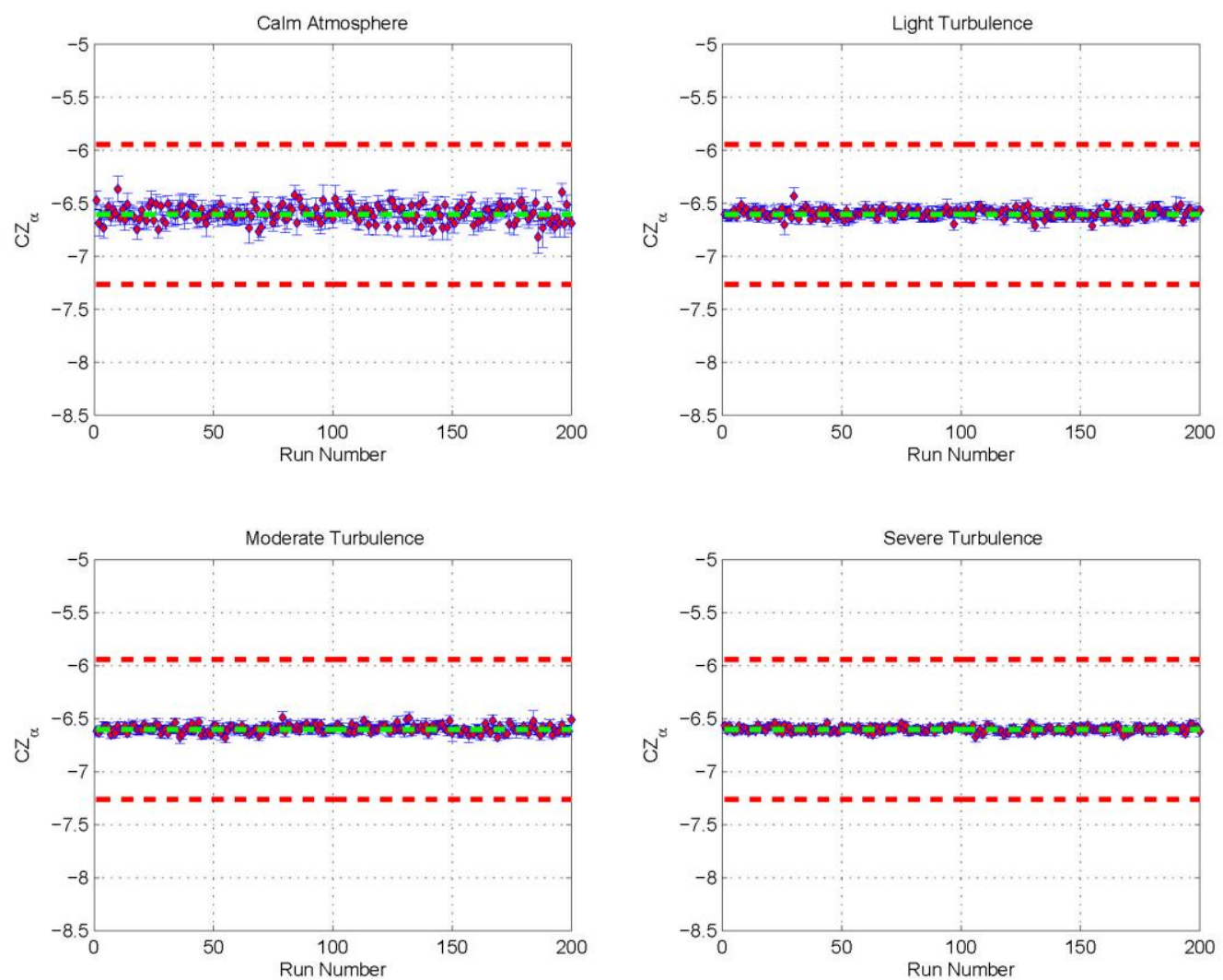

Figure 9. Test condition $1-$ effect on $C_{Z \alpha}$ 
As shown in Figure 10, the baseline model estimates for $C_{M \delta e}$ resulted in greater scatter as turbulence intensity increased. This is caused by noisy explanatory variables ${ }^{38}$ from the atmospheric turbulence implementation in Eq. (21). Similar patterns were observed with the remaining coefficients $C_{Z q}, C_{Z \delta e}, C_{M \alpha}$, and $C_{M q}$, although the results are not shown.
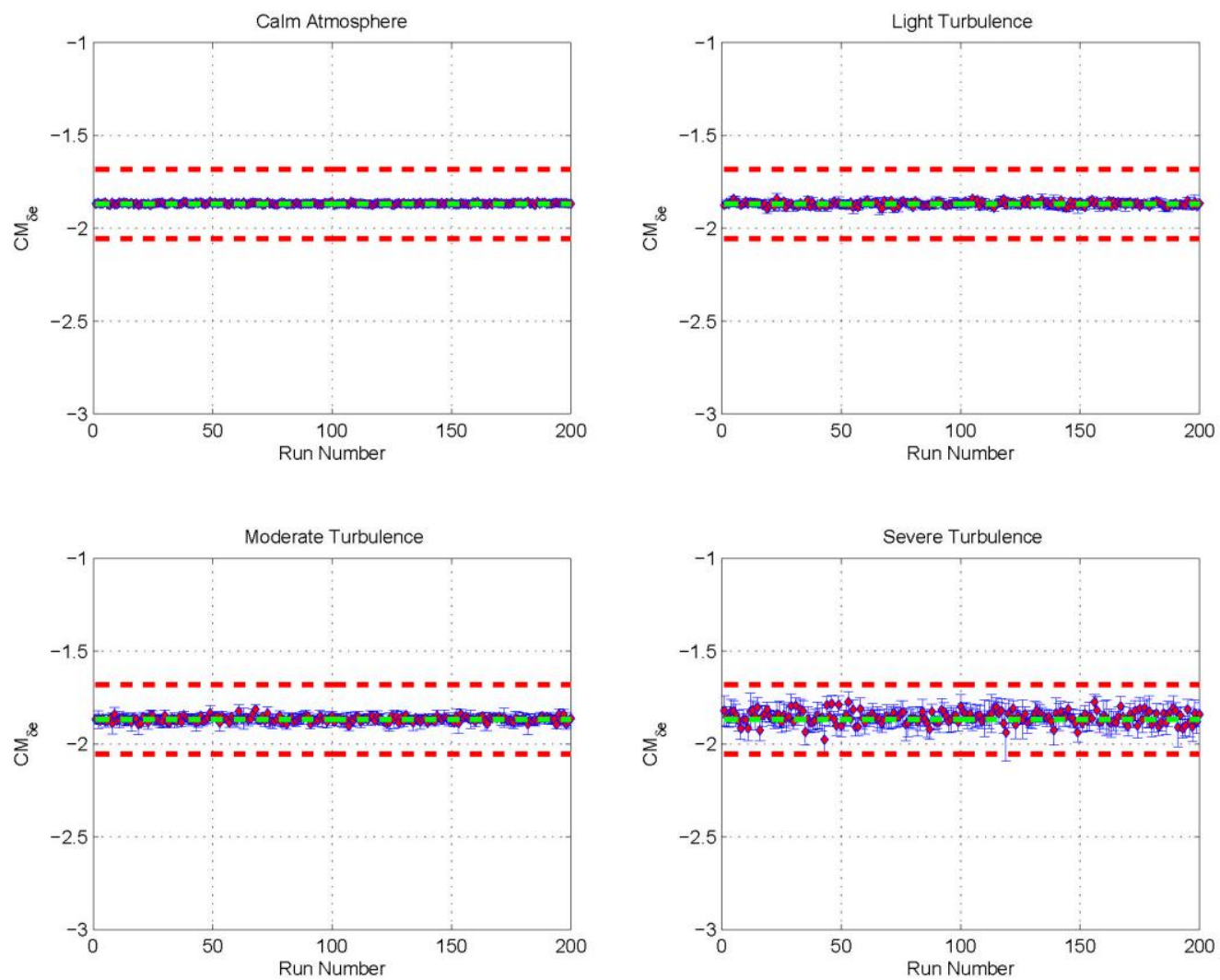

Figure 10. Test condition 1 - effect on $C_{M \delta e}$ 


\section{B. Test Condition 2}

Estimates for $C_{Z \alpha}$ based on the vane sensor model $\left(\omega_{n}=9 \mathrm{~Hz}\right.$ and $\left.\zeta=0.35\right)$ caused degradations and biasing in the estimates with increasing turbulence intensities, as shown in Figure 11. This is representative of actual flight data.
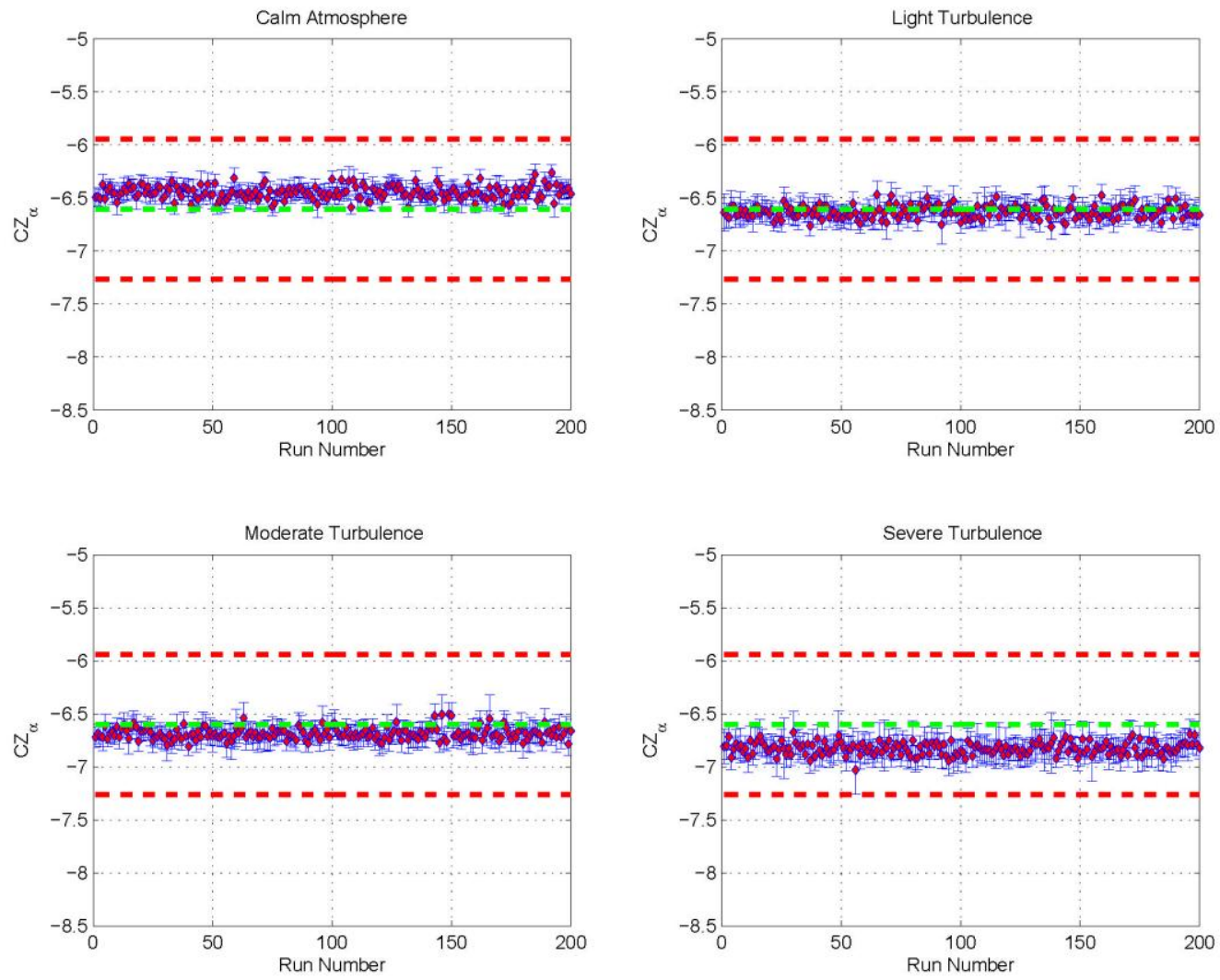

Figure 11. Test condition 2 - effect on $C_{Z \alpha}$ 
As shown in Figure 12, the baseline model estimates for $C_{M \delta e}$ resulted in greater scatter as atmospheric turbulence intensity increased. This is caused by noisy explanatory variables ${ }^{38}$ from the atmospheric turbulence implementation in Eq. (20), and the vane sensor model. Similar patterns were observed with the remaining coefficients $C_{Z q}, C_{Z \delta e}, C_{M \alpha}$, and $C_{M q}$. Results are not shown.
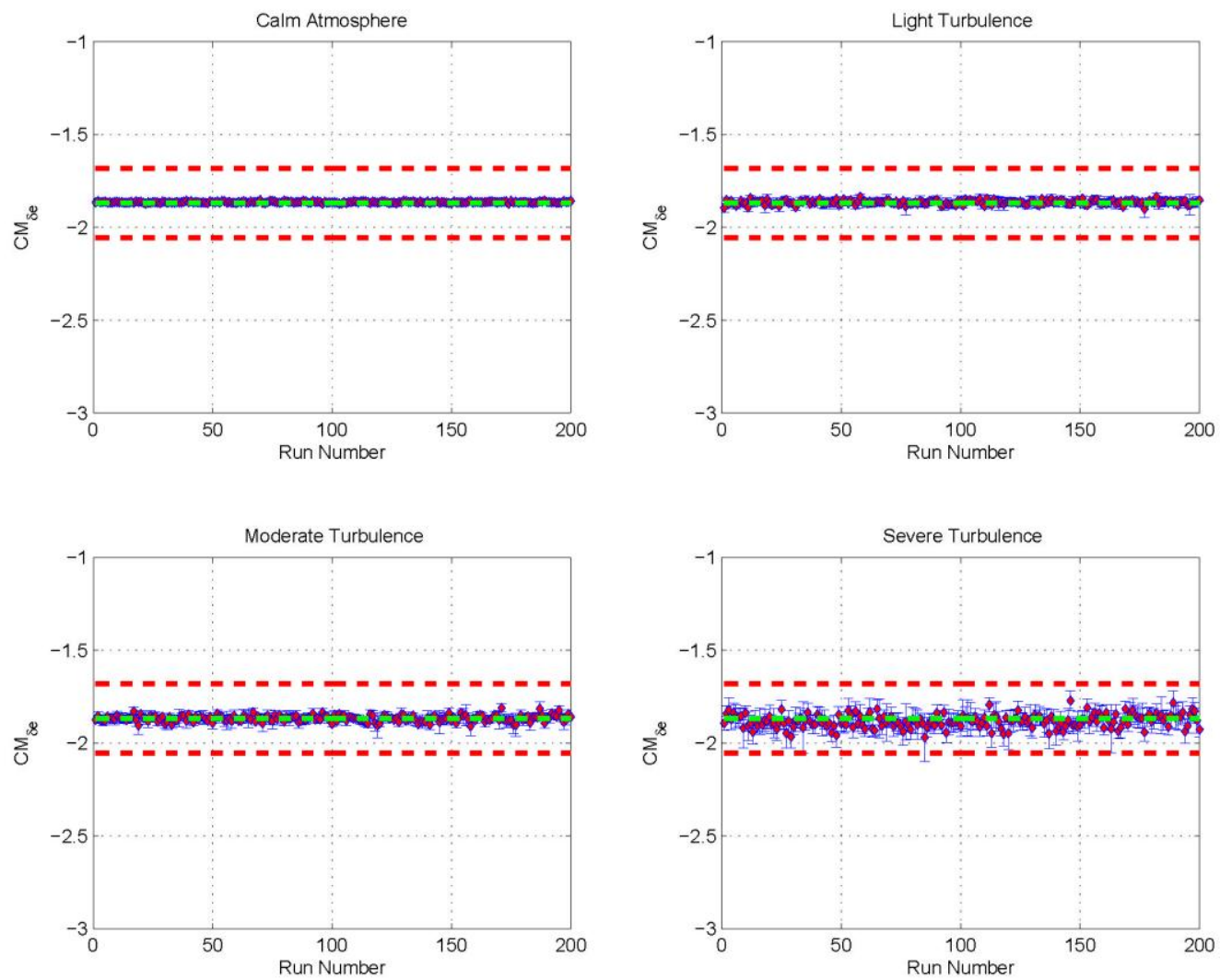

Figure 12. Test condition 2 - effect on $C_{M \delta e}$

\section{Test Condition 2 Expanded Testing}

Although no quantitative analysis was done, qualitatively, small differences were observed between a perfect and typical vane frequency response in test conditions 1 and 2. The vane dynamics do not substantially contribute to the scatter in the estimates, because all of the added dynamics are outside the range of frequencies analyzed.

To further validate this claim, additional testing was carried out using the same simulation. A total of 121 different combinations of flow angle vane natural frequency and damping ratios were tested. The natural frequency values tested were 5 through 15 in $1 \mathrm{~Hz}$ increments. The damping ratio values tested were $0.01,0.05,0.1,0.15,0.2$, $0.25,0.3,0.35,0.4,0.45$, and 0.6. Since the AIMMS-20 probe approaches a gain of one and zero phase shift, it is characterized by the results of test condition 1. The AIMMS-20 probe offers superior frequency response performance to mechanical vanes by using 1) a 5 hole pressure probe , 2) short tube lengths (air data tubes are typically less than 5 inches long), and 3) the resonance frequency of the silicon pressure diaphragm is in the kilohertz region. The following figures depict the results of 121 combinations, times 4 turbulence levels, times 200 runs per case. This totaled 96,800 runs. Figure 13 depicts the results of 96,800 runs for $C_{Z \alpha}$. As an example, the bottom left corner block in severe turbulence is light blue. The color represents the number of exceedances of $C_{Z \alpha}$ from $\pm 10 \%$ of truth. The remaining 120 blocks are dark blue representing less than 10 exceedences. Figure 13 
suggests that any combination of natural frequency and damping ratio tested provides adequate performance. Similar results were obtained for $C_{M \alpha}$ and $C_{M q}$. Results are not shown.
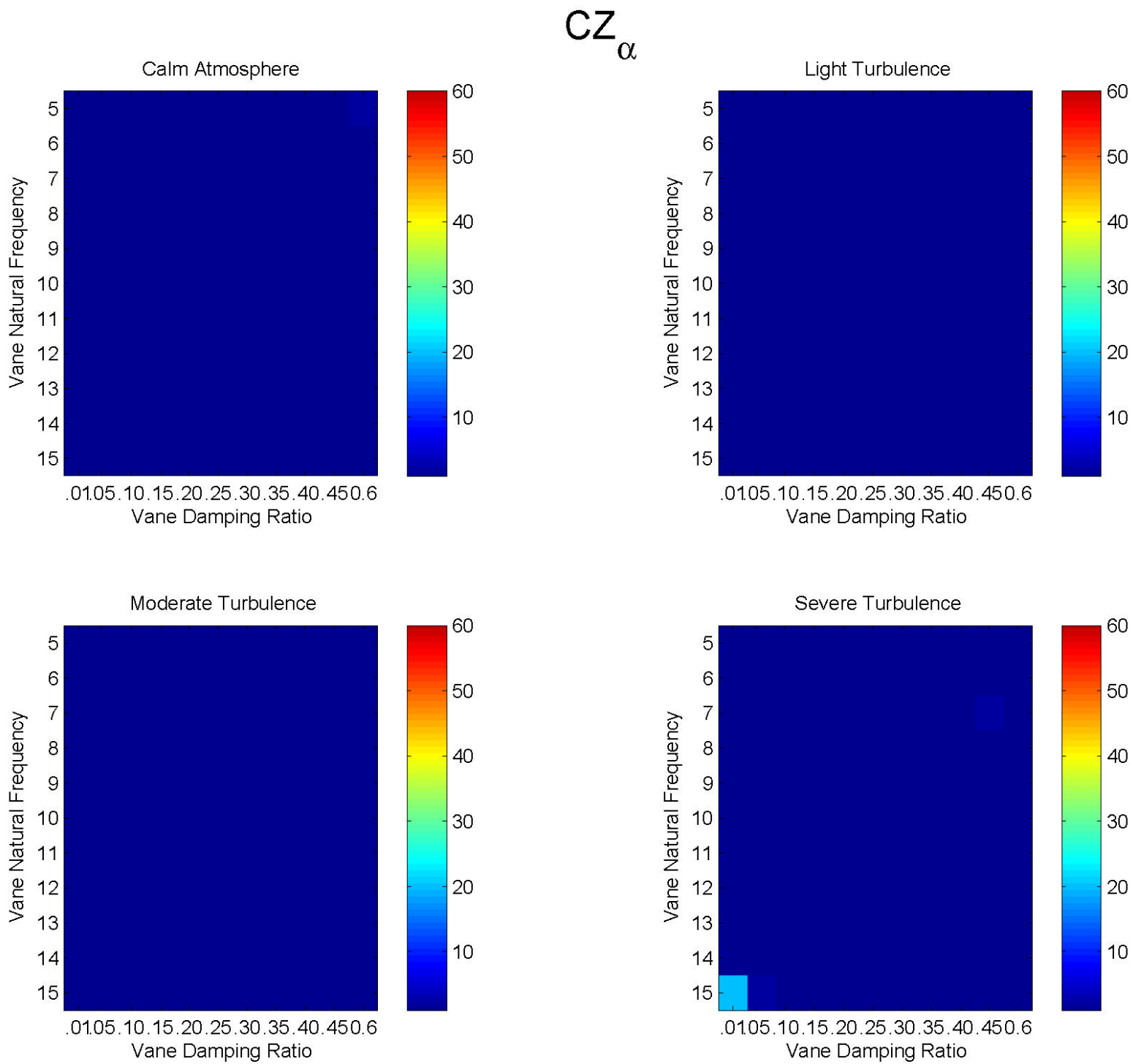

Number of Exceedence from $+/-10$ percent truth values - Defined per colorbar

Figure 13. Number of exceedances for $C_{Z \alpha}$ 
Figure 14 shows that independent of the natural frequency and damping ratio tested, accurate estimates of $C_{Z \delta e}$ are not feasible in atmospheric turbulence. This is expected since the normal force produced by elevator deflection , $C_{Z \delta e}$, is an order of magnitude less than the normal force produced by angle of attack, $C_{Z \alpha}$.
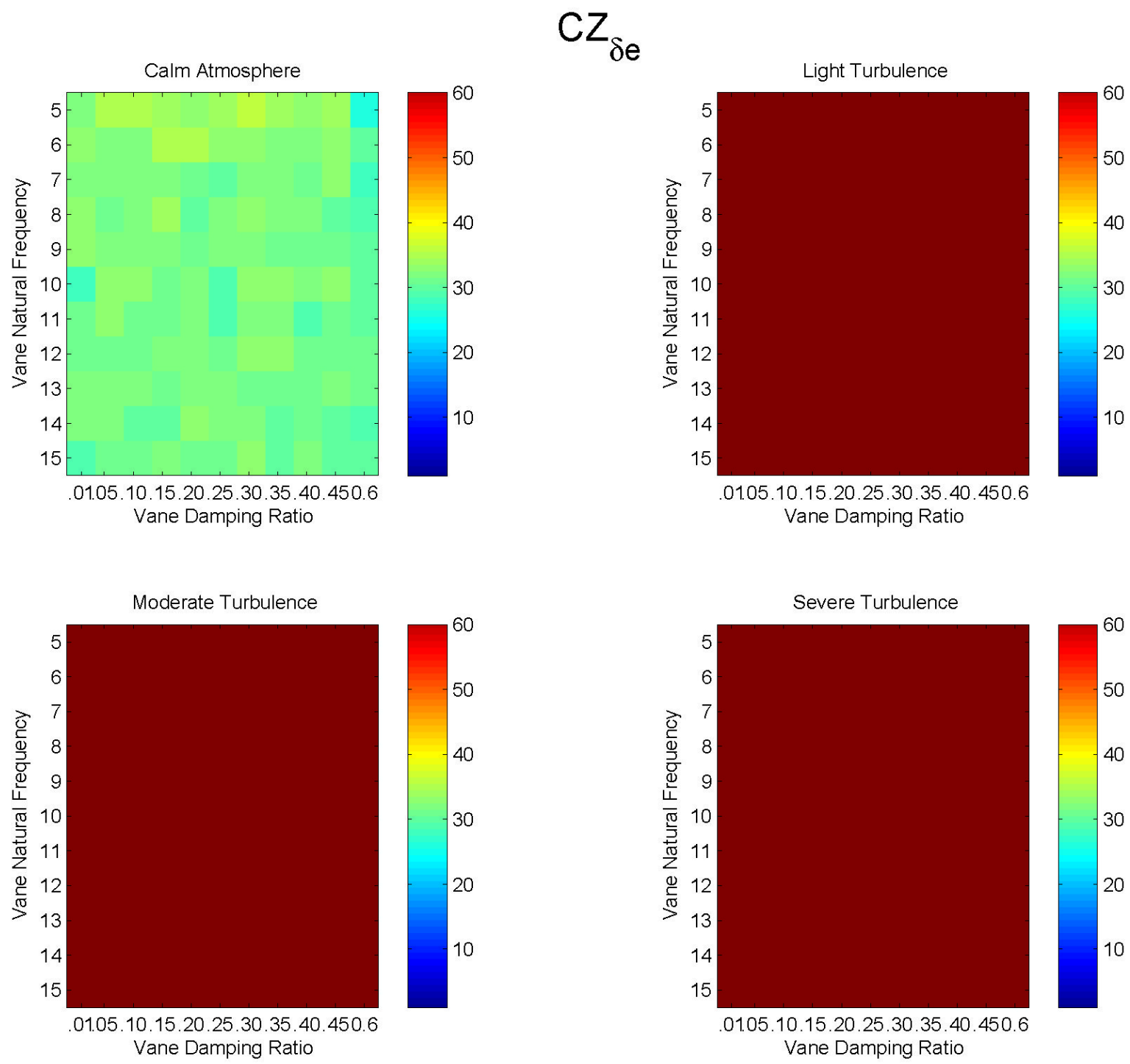

Number of Exceedence from +/- 10 percent truth values - Defined per colorbar

Figure 14. Number of exceedances for $C_{M q}$ 
Figures 15 shows that independent of the natural frequency and damping ratio tested, accurate estimates of $C_{M \delta e}$ are feasible in atmospheric turbulence. This is expected due to the elevator control authority.
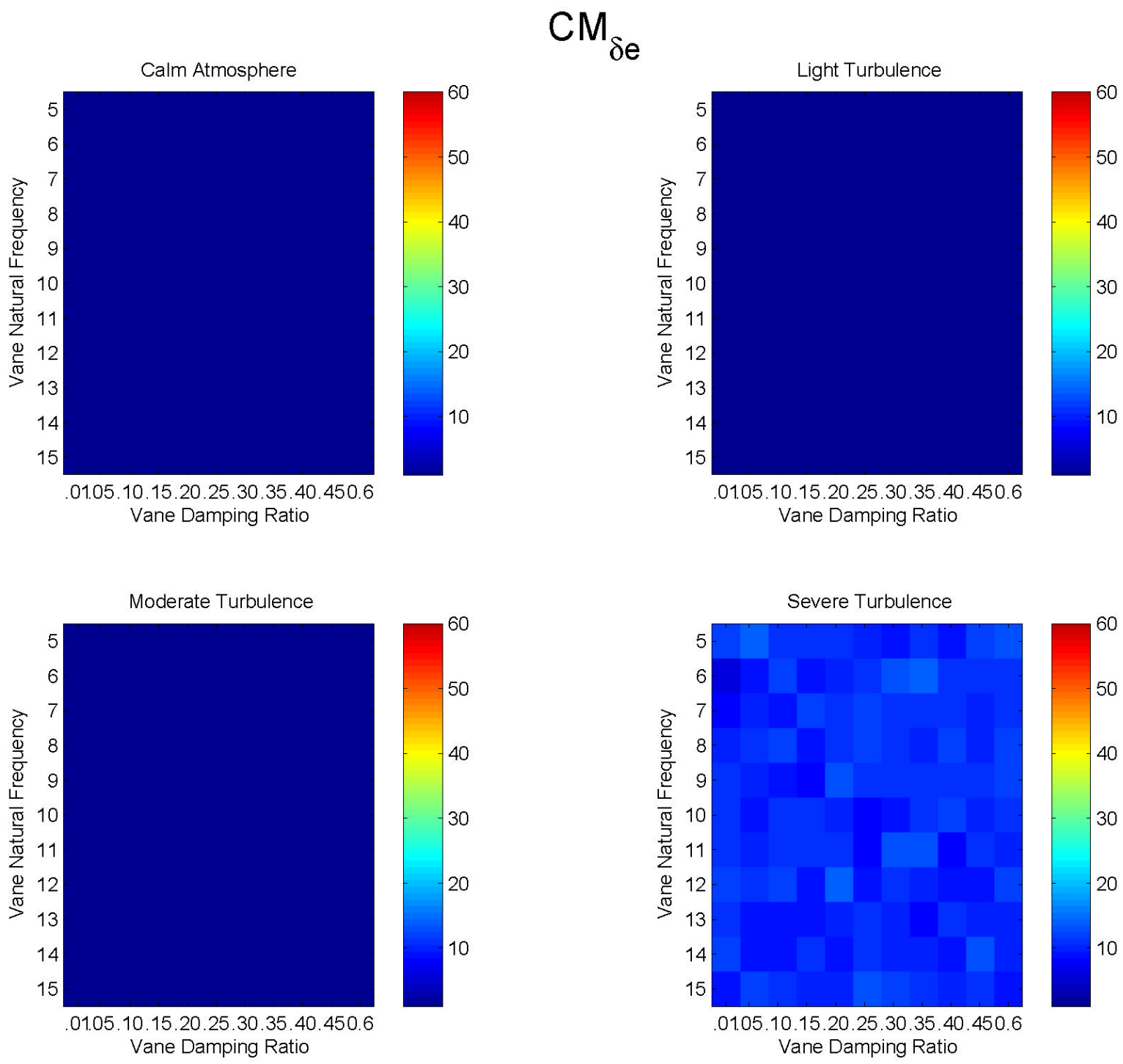

Number of Exceedence from +/- 10 percent truth values - Defined per colorbar

Figure 15. Number of exceedances for $C_{M \delta e}$

Results for $C_{Z q}$, not shown, demonstrate that independent of the natural frequency and damping ratio tested, estimates are not feasible in any level of atmospheric turbulence. For the remaining stability and control estimates the results show that most combinations of natural frequency and damping ratio tested provide adequate performance in calm, light, and moderate turbulence, and severe atmospheric turbulence. 


\section{Test Condition 3}

As shown in Figure 16, estimates for $C_{Z \alpha}$ resulted in degraded estimates with increasing atmospheric turbulence for varying angle of attack magnitude and time delay as a function of frequency. The degradation is seen as biasing in the estimates and increased scatter and uncertainty as the error bars increase. This is representative of actual flight data.
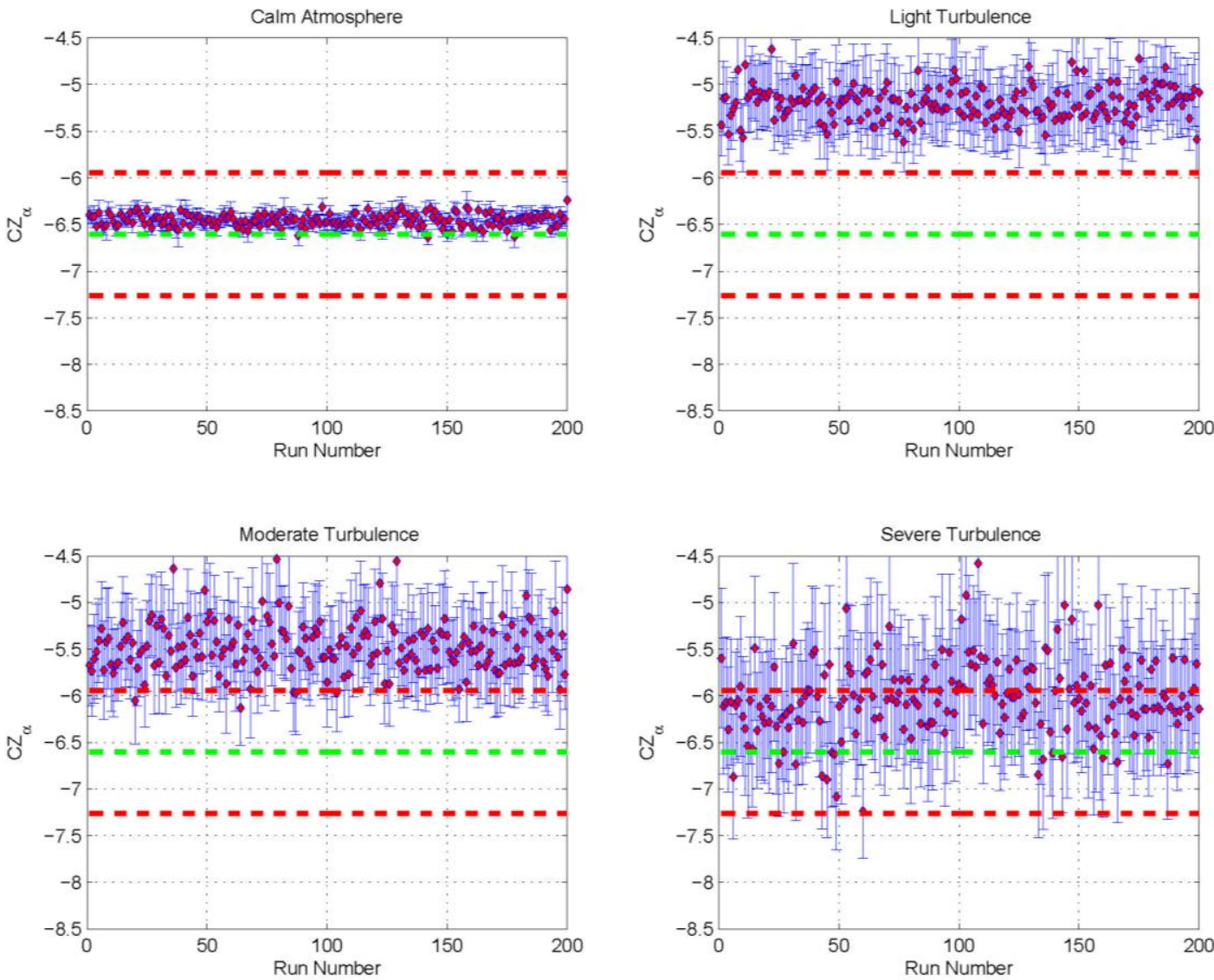

Figure 16. Test condition 3 - effect on $C_{Z \alpha}$ 
As shown in Figure 17, the estimates for $C_{Z \delta e}$ also resulted in degraded estimates with increasing atmospheric turbulence. The degradation is seen as biasing in the estimates and increased scatter and uncertainty as the error bars increase. The increase in biasing and uncertainty compared to $C_{Z \alpha}$ estimates is caused by the relatively small contribution of the elevator term to the normal force coefficient.
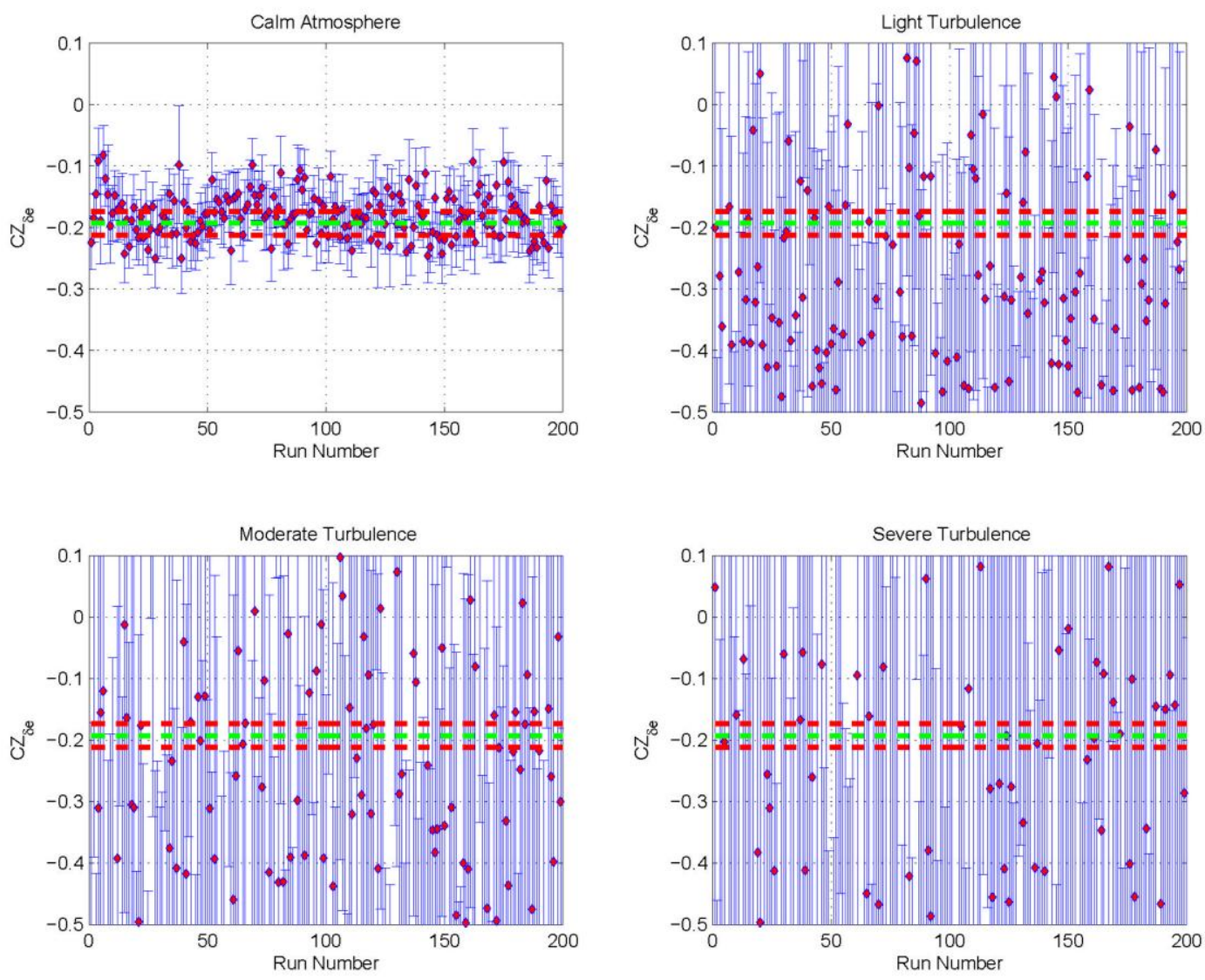

Figure 17. Test condition 3 - effect on $C_{Z \delta e}$ 
Figure 18 shows that the estimates for $C_{M \alpha}$ degraded with increasing atmospheric turbulence. The degradation is seen as biasing in the estimates and increased scatter and uncertainty as the error bars increase. This is representative of actual flight data.
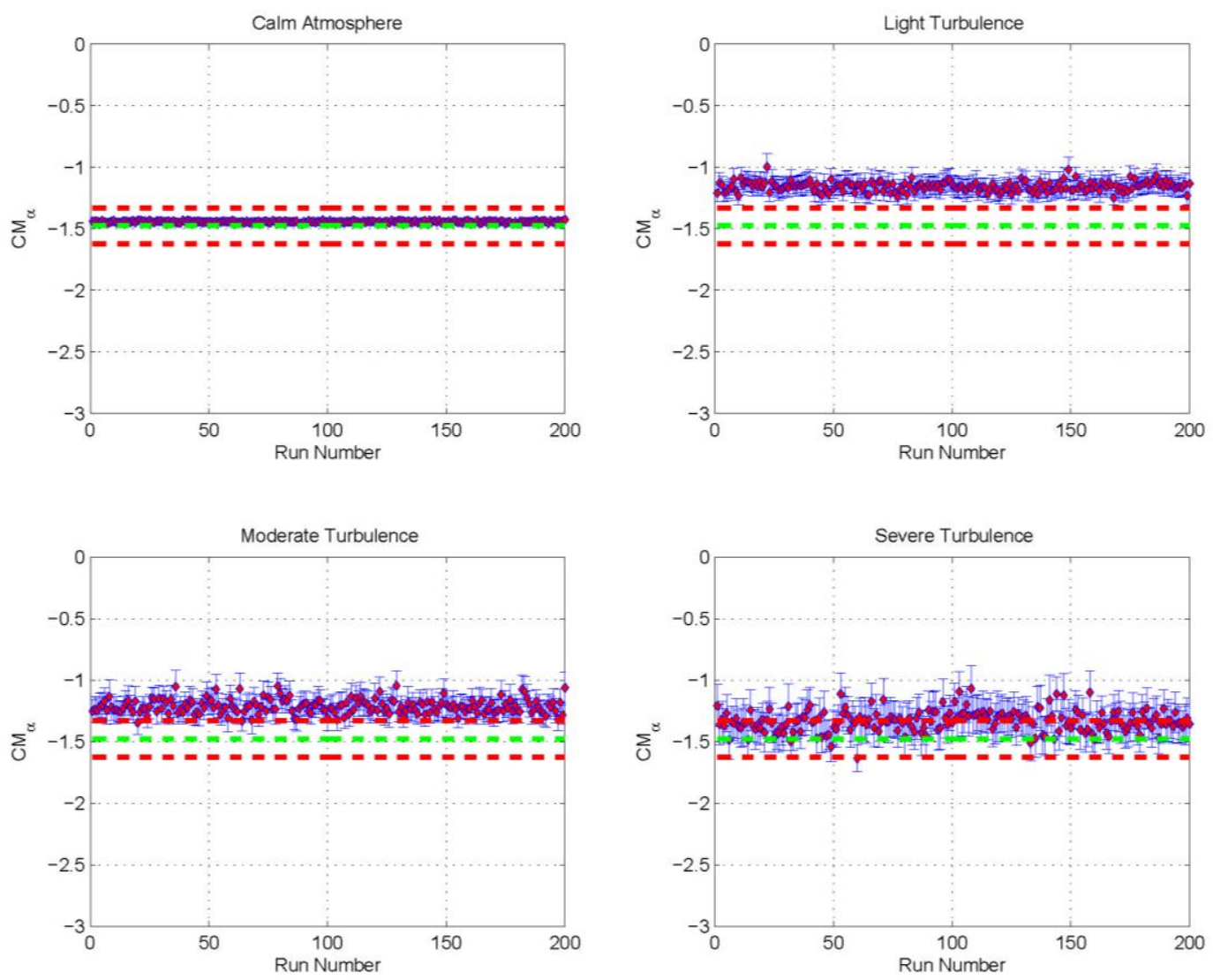

Figure 18. Test condition 3 - effect on $C_{M \alpha}$ 
As shown in Figure 19, the estimates for $C_{M q}$ degraded with increasing atmospheric turbulence. The degradation is seen as biasing in the estimates and increased scatter and uncertainty as the error bars increase. The estimates for $C_{M q}$ resulted in the largest biasing of all the aerodynamic estimates considered because angular velocity model parameters are most susceptible to time delays ${ }^{39}$.
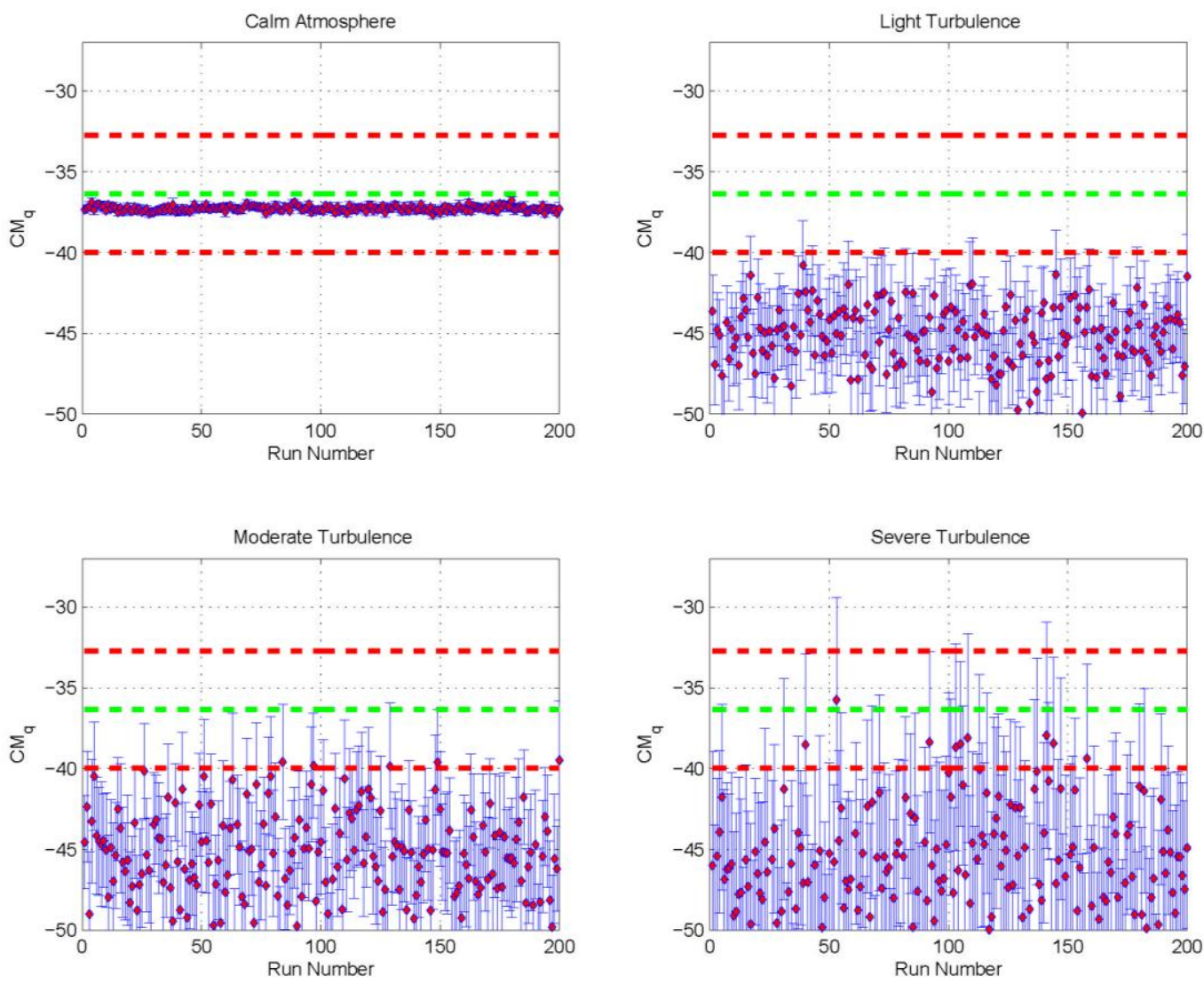

Figure 19. Test condition 3 - effect on $C_{M q}$ 
Figure 20 shows that the estimates for $C_{M \delta e}$ degraded with increasing atmospheric turbulence. The degradation is seen as a scatter in the estimates and increased scatter and uncertainty as the error bars increase. This is representative of actual flight data and correlates with the flight results presented in Figure 2.
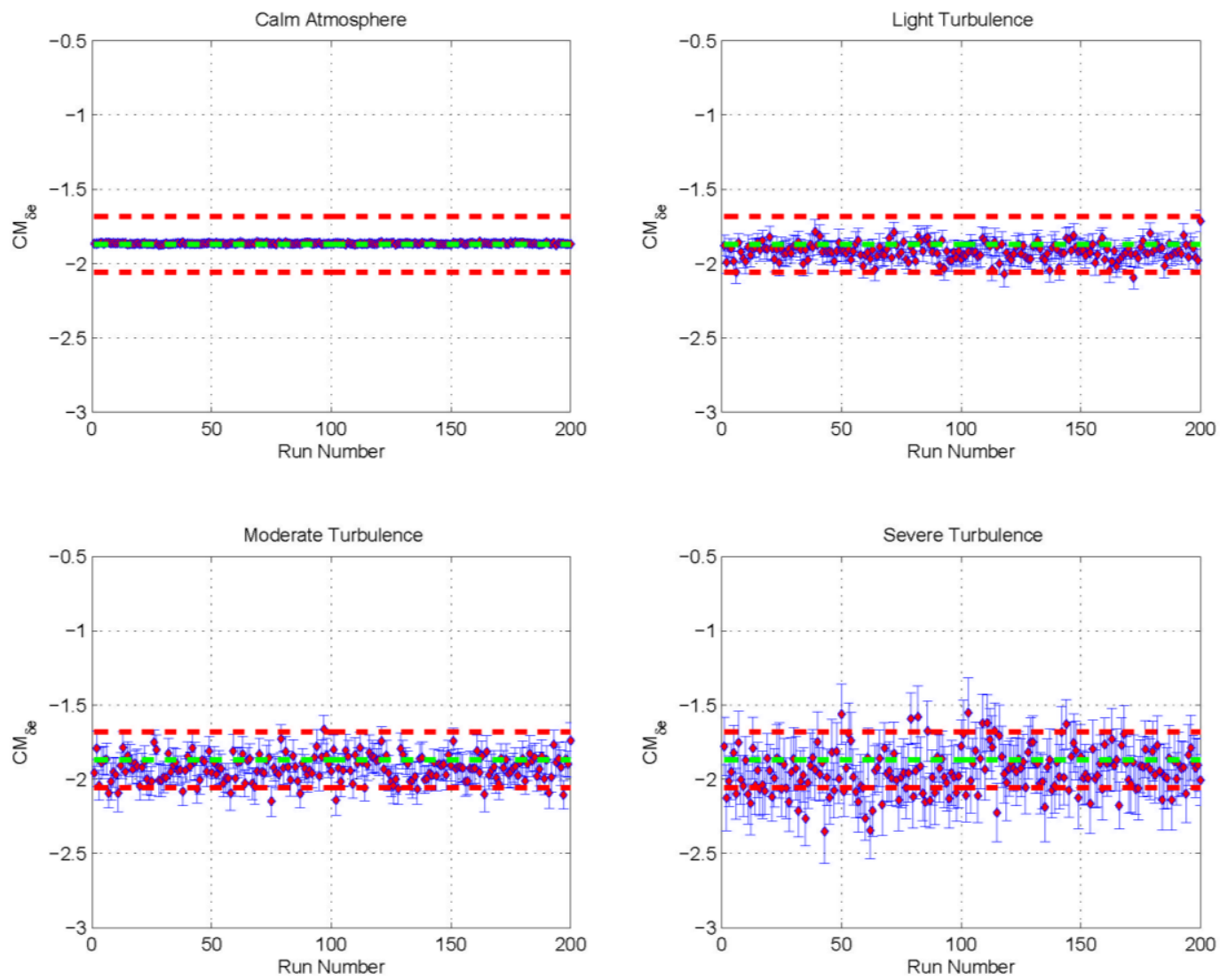

Figure 20. Test condition 3 - effect on $C_{M \delta e}$

Corrupting the angle of attack measurement by a frequency dependent magnitude and time delay affected all of the estimated stability and control coefficients. The estimates of $C_{M \alpha}$ and $C_{M \delta e}$ exhibited moderate biasing and increased scatter and uncertainty, $C_{Z \alpha}$ and $C_{M q}$ estimates had large biases and increased scatter and uncertainty, and $C_{Z \delta e}$ estimates showed the largest biases and increases in scatter and uncertainty. Previous work on the effects of time-shifted data on flight determined stability and control estimates ${ }^{39}$ using the output-error method in the time domain demonstrated identical trends in the biasing and increased uncertainty due to atmospheric turbulence. 


\section{Conclusions}

Several practical issues related to atmospheric turbulence in real-time estimation of parameters in a linear longitudinal dynamics model were examined and discussed. These issues included the use of COTS sensors and identifying sources of colored noise in the explanatory variables. It was determined that current COTS sensors compute the atmospheric turbulence and that any errors affecting an airdata boom and inertial navigation system will most likely affect COTS sensors. Therefore, current COTS atmospheric turbulence sensors do not offer an advantage over typical flight test hardware. The frequency response of the airflow vanes, wing response to atmospheric turbulence, and the structural response of the air data boom were identified as sources of colored noise. The frequency response of the airflow vanes for all combinations of natural frequency and damping ratio were adequate except for $C_{Z q}$ and $C_{Z \delta e}$ estimates in atmospheric turbulence. This is attributed to noisy explanatory variables in the atmospheric turbulence implementation and relatively low aerodynamic contributions as compared to $C_{Z \alpha}$. Therefore, the airflow vane dynamics themselves do not substantially contribute to the scatter in the estimates, because all of the added dynamics are outside the range of frequencies analyzed. A major source of colored noise is the frequency dependent upwash and time delay induced by the wing-bound vortex system and the longitudinal separation between the angle of attack measurement and the wing. The time delay in the angle of attack is the greatest contributor to biasing and increased scatter and uncertainty in the parameter estimates.

This approach enables the use of equation error methods in the frequency domain, without the need for tuning parameters and complex calculations typical of filter error methods. This is accomplished by accounting for the sources of the colored noise in the measurements instead of treating the source(s) as unknowns and accounting for them through the use of process noise.

Practical issues were examined using data from a Twin Otter DHC-6 longitudinal linear simulation, with realistic noise sequences added to the computed aircraft responses. This allowed a clear view of the effect of each source of colored noise to the modeling problem, because the true values of the model parameters were known. Flight test data from the NASA Glenn DHC-6 Twin Otter aircraft was used to validate the effect of the identified colored noise sources.

Based on these findings, several practical recommendations for atmospheric turbulence flight test are suggested as well as areas for future study. First, mount the airdata boom at the nose of the aircraft. If the airdata boom must be mounted on the wingtip, additional analytical techniques are needed to separate the aero elastic effect of the wing from the low frequency aircraft response. Second, if the airdata boom is mounted on the nose of the aircraft, an upwash and time delay calibration as a function of frequency is required. Third, for frequencies of interest, 0.1 to 2.0 $\mathrm{Hz}$, either airflow vanes or a pressured based measurements are adequate. Suggested areas for future study include the airspeed frequency response, model structure determination, lateral/directional real-time parameter estimation, as well as applying the frequency dependant upwash and time delay to obtain calm air estimates in atmospheric turbulence.

\section{Acknowledgments}

This work was sponsored by the National Aeronautics and Space Administration Grant NNX07AD58A and supervised by Thomas Ratvasky and Dr. Christine Belcastro. Discussions with Dr. John Kalogiros of the National Observatory of Athens are acknowledged and appreciated.

\section{References}

${ }^{1}$ Ranaudo, R., Martos, B., Norton, B., Gingras, D., Barnhart, B., Ratvasky, T., and Morelli, E., "Piloted Simulation to Evaluate the Utility of a Real Time Envelope System for Mitigating In-Flight Icing Hazards,"AIAA2010-7987.

${ }^{2}$ Maine, R.E. and Iliff, K.W., "Formulation and Implementation of a Practical Algorithm for Parameter Estimation with Process and Measurement Noise," SIAM Journal of Applied Mathematics, Vol. 41, No. 3, 1981, pp. 558-579.

${ }^{3}$ Maine, R.E. and Iliff, K.W., "Identification of Dynamic Systems,” AGARD AG-300 Vol. 2, Jan. 1985. 
${ }^{4}$ Jategaonkar, R.V., “A comparison of Output Error and Filter Error Methods from Aircraft Parameter Estimation Results," Proceedings of the NAL-DLR Symposium on System Identification, DLR-Mitt. 93-14, Dec. 1993, pp. 6387.

${ }^{5}$ Iliff, K. W., "Identification and Stochastic Control With Application to Fight Control in Turbulence," UCLAENG-7340, School of Engineering and Applied Science, Univ. Calif., Los Angeles, CA, May 1973.

${ }^{6}$ Iliff, K.W., "Estimation of Characteristics and Stochastic Control of an Aircraft Flying in Atmospheric Turbulence," Proceedings ofAIAA 3rd Atmospheric Flight Mechanics Conference, 1976, pp. 26-38.

${ }^{7}$ Iliff, K.W., "Identification of Aircraft Stability and Control Derivatives in the Presence of Turbulence," Parameter Estimation Techniques and Applications in Aircraft Flight Testing, NASA TN D-7647, 1974, pp. 77-113.

${ }^{8}$ Maine, R.E. and Iliff, K.W., "Formulation and Implementation of a Practical Algorithm for Parameter Estimation with Process and Measurement Noise," SIAM Journal on Applied Mathematics, Vol. 41, No. 3, Dec. 1981, pp. 558-579.

${ }^{9}$ Jategaonkar, R.V., Flight Vehicle System Identification: A Time Domain Methodology, AIAA, Reston, VA, 2006.

${ }^{10}$ Klein, V and Morelli, E.A., Aircraft System Identification Theory and Practice, AIAA Education Series, Reston, VA, 2006.

${ }^{11}$ Morelli, E.A., "Real-Time Parameter Estimation in the Frequency Domain," Journal of Guidance, Control, and Dynamics, Vol. 23, No. 5, September-October 2000, pp. 812-818.

${ }^{12}$ Morelli, E.A., "System IDentification Programs for AirCraft (SIDPAC),” AIAA-2002-4704.

${ }^{13}$ Stromberg, I. M., Mill, C. S., Choularton, T. W., and Gallagher, M.W., "A case study of stably stratified airflow over the Pennines using an instrumented glider,” Boundary-Layer Meteorology, 46, 1989, pp. $153-168$.

${ }^{14}$ Notess, C.B. and Eakin, G.J., "Flight-test investigation of turbulence spectra at low altitude using a direct method for measuring gust velocities," Wright Air Development Center Technical Report WADC 54-309, 1954, pp. 54-309.

${ }^{15}$ Telford, J. W. and Warner, J., "On the measurement from an aircraft of buoyancy and vertical air velocity in cloud," J. Atmos. Sci., 19, 1962, pp. 415-423.

${ }^{16}$ Johnson, H. D., Lenschow, D. H., and Danninger, K., “A new fixed vane for air motion sensing,” Proceedings of the Fourth Symposium on Meteorological Observations and Instrumentation, Denver, CO, April 1978, pp. 487491.

${ }^{17}$ Lenschow, D. H., "Vanes for sensing incidence angles of the air from an aircraft," J. Appl. Meteor., 10, 1971, pp. 1339-1343.

${ }^{18}$ Brown, E. N., Friehe, C. A., and Lenschow, D. H., "The use of pressure fluctuations on the nose of an aircraft for measuring air motion," J. Climate Appl. Meteor., 22, 1983, pp. 171-180.

${ }^{19}$ Tjernstrom, M., and C.A. Friehe, "Analysis of a radome airmotion system on a twin-jet aircraft for boundarylayer research," J. Atmos. Oceanic Technol,. 8, 1991, pp. 19-40.

${ }^{20}$ Khelif, D., S.P. Burns, and C.A. Friehe, "Improved wind measurements on research aircraft," J. Atmos. Oceanic Technol,. 16, 1999, pp. 860-875.

${ }^{21}$ Wyngaard, J.C., "The Effects of Probe-Induced Flow Distortion on Atmospheric Turbulence Measurements," Journal of Applied Meteorology, 20, 1981, pp. 784-794.

${ }^{22}$ Wood, R., Stromberg, I.M., Jonas, P.R., and Mill, C.S. "Analysis of an Air Motion System on a Light Aircraft for Boundary Layer Research,” J. Atmos. Oceanic Technol., 14, 1997, pp. 960-968.

${ }^{23}$ Hacker, J. M. and Crawford, T., "The Bat-Probe: The ultimate tool to measure turbulence from any kind of aircraft (or sailplane)," J. Technical Soaring, 13, 1999, pp. 43-46.

${ }^{24}$ Crawford, Timothy J. and Dobosy, Ronald J., "A Sensitive Fast-Response Probe to Measure Turbulence and Heat Flux from Any Airplane,” Boundary-Layer Meteorology, 59, 1992, pp. 257-278. 
${ }^{25}$ Garman, K. E., “An Airbourne and Wind Tunnel Evaluation of a Wind Turbulence Measurement System for Aircraft-Based Flux Measurements," Journal of Atmospheric and Oceanic Technology, 23, 2006, pp. 1696-1708.

${ }^{26}$ Lawless, Al, "Inertial-Based Instrumentation for Performance Flight Testing," SFTE Symposium XX Proceedings, 2008.

${ }^{27}$ Olson, W., “Aircraft Performance Flight Testing,” AFFTC-TIH-99-01, Edwards AFB, CA, Sept. 2000.

${ }^{28}$ Advisory Group for Aeronautical Research and Development, "Flying Qualities Flight Testing of Digital Flight Control Systems," Flight Test Techniques Series - RTO AG-300, Volume 21, Dec. 2001, pp. 58-60.

${ }^{29}$ Michigan Aerospace, "MOADS product overview,".

URL: http://www.michiganaero.com/business_units/oads/moads.shtml [cited 14 June 2012].

${ }^{30}$ Aeroprobe Corporation, "Fast Response Probe product overview,"

URL: http://www.aeroprobe.com/uploads/Aeroprobe-Fast-Response-Probe-2012.pdf [cited 14 June 2012].

${ }^{31}$ Aventech Research Incorporated, “AIMMS-20 product overview,"

URL: http://www.aventech.com/products/aimms20.php [cited 14 June 2012].

${ }^{32}$ Lenschow, D.H., "Vanes for sensing incidence angles of the air from an aircraft," Journal of Applied Meteorology, 10, 1971, pp. 1339-1343.

${ }^{33}$ Sakamoto, G.M., "Aerodynamic Characteristics of a Vane Flow Angularity Sensor System Capable of Measuring Flight Path Accelerations for the Mach Number Range from 0.40 to 2.54," NASA TN-D8242, 1976.

${ }^{34}$ Foster, G.W, "The Identification of Aircraft Stability and Control Parameters in Turbulence," PhD Thesis, Cranfield Institute of Technology, 1982.

${ }^{35}$ Kalogiros, John A., Qing Wang, “Aerodynamic Effects on Wind Turbulence Measurements with Research Aircraft,” J. Atmos. Oceanic Technol., 19, 2002, pp. 1567-1576.

${ }^{36}$ Kalogiros, J. A., and Q. Wang, "Calibration of a radome-differential GPS system on a Twin Otter research aircraft for turbulence measurements," J. Atmos. Oceanic Technol., 19, 2002, pp. 159-171.

${ }^{37}$ Mathworks, "Dryden Wind Turbulence Model (Discrete),"

URL: http://www.mathworks.com/help/toolbox/aeroblks/drydenwindturbulencemodeldiscrete.html

[Accessed 1/20/12.]

${ }^{38}$ Morelli, E.A., "Practical Aspects of the Equation-Error Method for Aircraft Parameter Estimation," AIAA2006-6144.

${ }^{39}$ Steers, S.T. and Iliff, K.W., "Effects of Time-Shifted Data on Flight-Determined Stability and Control Derivatives," NASA TN D-7830, 1975. 